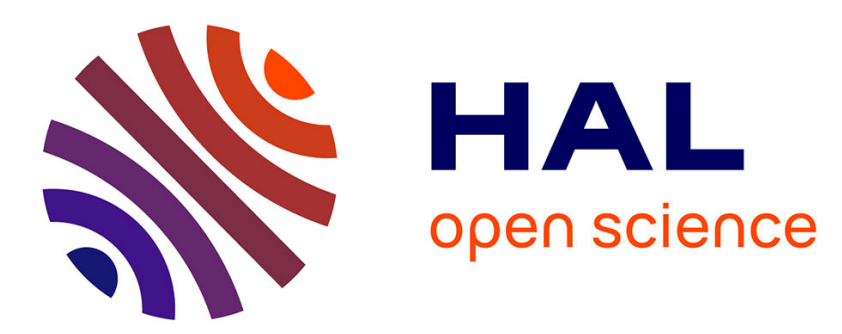

\title{
Tetrabromobisphenol A acts a neurodevelopmental disruptor in early larval stages of Mytilus galloprovincialis
}

\author{
A. Miglioli, T. Balbi, M. Montagna, Remi Dumollard, L. Canesi
}

\section{To cite this version:}

A. Miglioli, T. Balbi, M. Montagna, Remi Dumollard, L. Canesi. Tetrabromobisphenol A acts a neurodevelopmental disruptor in early larval stages of Mytilus galloprovincialis. Science of the Total Environment, 2021, 793, pp.148596. 10.1016/j.scitotenv.2021.148596 . hal-03373408

\author{
HAL Id: hal-03373408 \\ https://hal.science/hal-03373408
}

Submitted on 18 Oct 2021

HAL is a multi-disciplinary open access archive for the deposit and dissemination of scientific research documents, whether they are published or not. The documents may come from teaching and research institutions in France or abroad, or from public or private research centers.
L'archive ouverte pluridisciplinaire HAL, est destinée au dépôt et à la diffusion de documents scientifiques de niveau recherche, publiés ou non, émanant des établissements d'enseignement et de recherche français ou étrangers, des laboratoires publics ou privés. 
POSSIBLE AOP FOR TBBPA IN EARLY LARVAL DEVELOPMENT OF MYTILUS GALLOPROVINCIALIS

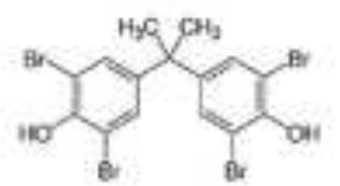

MOLECULAR INITIATING EVENT
KEY EVENTS
EFFECTS ON INDIVIDUALS

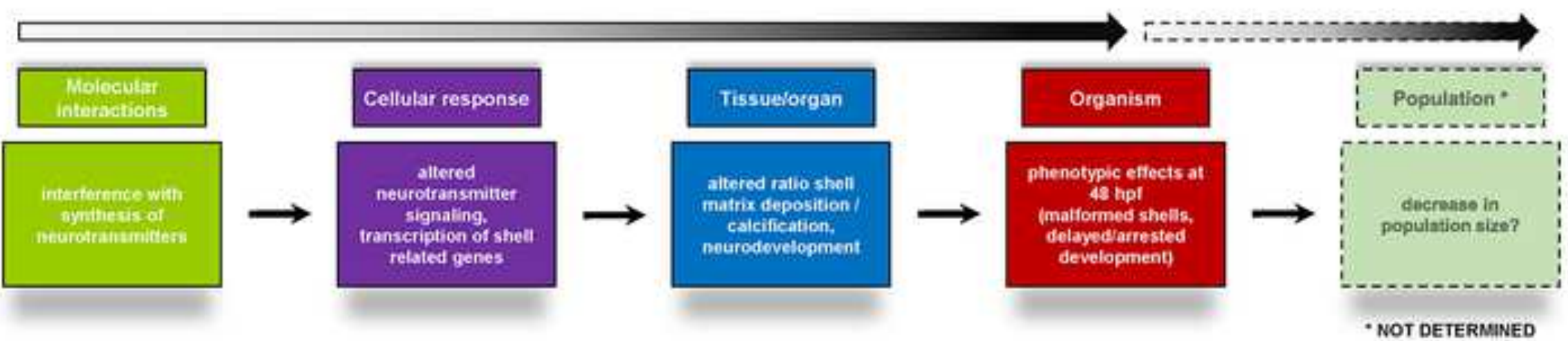


Highlights (for review : 3 to 5 bullet points (maximum 85

characters including spaces per bullet point)

\section{Highlights}

- Tetrabromobisphenol A-TBBPA affects early larval development in Mytilus

- Effects on shell formation, organic matrix and $\mathrm{CaCO}_{3}$ deposition

- Altered expression pattern of genes involved in shell biogenesis from $28 \mathrm{hpf}$

- From 24 hpf impairment of serotonin, GABA and dopamine systems

- TBBPA acts as a neurodevelopmental disruptor in mussel early larval stages 
19 Tetrabromobisphenol A-TBBPA, a widely used brominated flame retardant detected in aquatic environments, is considered a potential endocrine disruptor-ED for its reproductive/developmental effects in vertebrates. In aquatic invertebrates, the modes of action of most EDs are largely unknown, due to partial knowledge of the mechanisms controlling neuroendocrine functions. In the marine bivalve Mytilus galloprovincialis, TBBPA has been previously shown to affect larval development in the 48 hours larval toxicity assay at environmental concentrations. In this work, the effects of TBBPA were further investigated at different times post-fertilization. TBBPA, from $1 \mu \mathrm{g} / \mathrm{L}$, affected shell biogenesis at 48 hours post fertilization-hpf, as shown by phenotypic and SEM analysis. The mechanisms of action of TBBPA were investigated at concentrations of the same order of magnitude as those found in highly polluted coastal areas $(10 \mu \mathrm{g} / \mathrm{L})$. At 28-32 hpf, TBBPA significantly affected deposition of both the organic matrix and $\mathrm{CaCO}_{3}$ in the shell. TBBPA also altered expression of shell-related genes from 24 to $48 \mathrm{hpf}$, in particular of tyrosinase, a key enzyme in shell matrix remodeling. At earlier stages (24 hpf), TBBPA affected the development of dopaminergic, serotoninergic and GABAergic systems, as shown by in situ hybridization-ISH and immunocytochemistry. These data contribute draw adverse outcome pathways-AOPs, where TBBPA affects the synthesis of neutrotransmitters involved in key events (neurodevelopment and shell biogenesis), resulting in phenotypic changes on individuals (delayed or arrested development) that might lead to detrimental consequences on populations.

Keywords: tetrabromobisphenol A, Mytilus, early larval stages, shell formation, neuroendocrine 39 disruptor 


\section{Introduction}

Tetrabromobisphenol A (TBBPA) is one of the most widely used brominated flame retardants in the production of epoxy and polycarbonate resins employed in electronic devices, furniture, plastics, textiles, and other products (Covaci et al., 2009). TBBPA is highly produced worldwide, and its global market is expected to increase over the next five years (WorldAnalytics, 2019). EPA designated TBBPA as a high priority chemical currently undergoing risk evaluation (EPA, 2019). TBBPA is frequently detected in different ecosystem compartments, including aquatic environments (Liu et al., 2016; Zhou et al., 2020) and it can be also accumulated in the food chain (Morris et al., 2004; Yang et al., 2012; Shi et al., 2017).

TBBPA is likely to reach the marine environment largely through industrial waste waters from landbased industrial activities, and coastal areas worldwide are subjected to increasing TBBPA contamination, thus raising great environmental concern (Gu et al., 2019). Levels of TBBPA in urbanized coastal areas range from ng to $\mu \mathrm{g}$ in both sediments $\left(\mathrm{g}^{-1} \mathrm{dw}\right)$ and waters $\left(\mathrm{L}^{-1}\right)$ (Liu et al., 2016; Sühring et al., 2015; Gong et al., 2017 and refs therein). High concentrations (>1 $\left.\mu \mathrm{g} \mathrm{L}^{-1}\right)$ detected at polluted sites (Liu et al., 2016; Gong et al., 2017; Li et al., 2020) are comparable to TBBPA levels in urban soils and freshwater, suggesting that coastal seawater may receive discharge from industrial effluents or landfill leakages without effective treatment.

Due to its almost ubiquitous presence, the potential impact of TBBPA on human and environmental health has been widely investigated (Wang et al., 2020; Zhou et al., 2020). Studies based on cell and animal models (mammals and fish) have demonstrated that TBBPA can induce pleiotropic effects on liver, kidney, heart, neural and reproductive functions; in particular, TBBPA has been shown to be a potential endocrine disruptor (ED), because of its reproductive and developmental effects including interference with thyroid hormone signalling (Zhang et al., 2014; Zhou et al., 2020). Significant effects of TBBPA on early embryo development have been observed in mammalian and zebrafish models in the nmol/L range, underlying that particular attention should be paid to the potential effects of TBBPA on early developmental stages (Zhou et al., 2020). Moreover, it has been shown that 
molluscan shell growth may be uniquely sensitive to TBBPA, more sensitive than chronic fish or crustacean toxicity endpoints (Pittinger and Pecquet, 2018).

We have previously demonstrated that in the model marine bivalve, the mussel Mytilus galloprovincialis, environmental concentrations of TBBPA affected early larval development evaluated in the standard $48 \mathrm{~h}$ embryotoxicity assay, with a LOEC of $0.1 \mu \mathrm{g} / \mathrm{L}$ and an $\mathrm{EC}_{50}$ of 5.52 $\mu \mathrm{g} / \mathrm{L}$ (Fabbri et al., 2014). The effects were comparable with those observed with the parent compound Bisphenol A-BPA (Fabbri et al., 2014), that has been subsequently shown to interfere with the molecular mechanisms involved in shell biogenesis and development of the serotoninergic system in early mussel larvae (Balbi et al., 2016; Miglioli et al., 2021a).

In this work, the effects and mechanisms of action of TBBPA were further investigated in mussel larvae at different times post fertilization, with special emphasis on early shell formation, the key step in the transition from the trocophora ( $24 \mathrm{hpf})$ to the first D-veliger stage (48 hpf), as well as on neurodevelopment. Concentrations were chosen among those encompassing the $\mathrm{EC}_{50}$ values obtained in the $48 \mathrm{~h}$ larval developmental assay ( 1 and $10 \mu \mathrm{g} / \mathrm{L}$, depending on the endpoint measured) (Fabbri et al., 2014), and environmental levels detected in polluted coastal areas (Liu et al., 2016, Gong et al., 2017; Li et al., 2020). Higher, embryotoxic concentrations (100 $\mu \mathrm{g} / \mathrm{L})$ (Fabbri et al., 2014) were also utilized to evaluate the effects on shell formation at earlier stages.

The effects of TBBPA on shell biogenesis were investigated by different techniques, following the experimental setup previously described (Miglioli et al., 2019, 2021a). Deposition of the organic matrix and of the calcified shell were evaluated at 24, 28, 32, and 48 hpf by Calcofluor/Calcein staining, and quantified by digital imaging. In addition, shell morphology at 48 hpf was investigated by Scanning Electron Microscopy-SEM. Across different developmental stages, expression of key genes involved in shell matrix deposition (chitin synthase-CS; tyrosinase-TYR) and calcification (carbonic anhydrase-CA; extrapallial protein-EP) was quantified by qPCR; the expression pattern of tyrosinase and chitinase was also evaluated by In Situ Hybridization-ISH. 
Moreover, the possible effects of TBBPA on neurodevelopment were investigated focusing on the main neurotransmitters identified in bivalves (Liu et al., 2018; Joyce and Vogeler, 2018). Localization of components of the dopaminergic system (Tyrosine Hydroxylase-TH, Dopamine- $\beta$-Hydroxylase$\mathrm{D} \beta \mathrm{H}$, Dopamine Receptor 1-DR1) was investigated by ISH; development of serotoninergic and GABAergic neurons was evaluated by immunohistochemistry.

\section{Methods}

\subsection{Mussels, larval development and exposure conditions}

All procedures were carried out as previously described (Miglioli et al., 2019, 2021a). Sexually mature specimens of M. galloprovincialis were collected from a natural population in the Bay of Villefranche-sur-mer $\left(43.682^{\circ} \mathrm{N}, 7.319^{\circ} \mathrm{E}\right.$ - France) during the spawning season of $2019 / 20$ (December-March). Animals were maintained at the Institut de la Mer de Villefranche (IMEV) by the Centre de Ressources Biologiques Marines of the institute (CRBM), transferred to the laboratory and acclimatized in flow-through vessels containing filtered natural seawater MFSW (Millipore filtered seawater) $\left(\mathrm{pH} 7.9-8.0,38 \mathrm{ppt}\right.$ salinity, $\left.15^{\circ} \mathrm{C}\right)$.

Gametes were obtained by spontaneous spawning; after checking egg quality (shape, size) and sperm motility, fertilization was carried out with an egg:sperm ratio of 1:10. After $30 \mathrm{~min}$, fertilization success (n. fertilized eggs/n. total eggs x 100) was verified by microscopic observation (usually > $90 \%)$. Fertilized eggs were transferred to 24 -well plates $\left(200\right.$ larvae $\left.\mathrm{mL}^{-1}\right)$ and exposed to TBBPA 3,3',5,5'-Tetrabromobisphenol A (Sigma-Aldrich, Milan), from stock solutions (0.5 M in Dimethylsulfoxide/DMSO) suitably diluted in filtered marine sea water-MFSW to obtain the selected final concentrations. Parallel control samples were run in MFSW added with 0.01\% DMSO. In all experimental conditions, samples were represented by larvae obtained from 5 independent parental pairs $(\mathrm{N}=5)$, unless otherwise indicated.

TBBPA final concentrations ( 1 and $10 \mu \mathrm{g} / \mathrm{L}$, corresponding to 1.8 and $18 \mathrm{nM}$, respectively), depending on the endpoint measured, were chosen among those encompassing higher levels detected 
in polluted coastal areas (Gong et al., 2017; Li et al., 2020), as well as the $\mathrm{EC}_{50}$ values previously obtained for TBBPA in the $48 \mathrm{~h}$ embryotoxicity assay (Fabbri et al., 2014). Higher, embryotoxic concentrations $(100 \mu \mathrm{g} / \mathrm{L})$ were also utilized to confirm the effects on shell formation at early stages. Concentrations in test solutions were checked by LC/MS as previously described (Fabbri et al., 2014).

\subsection{Effect of TBBPA on shell formation}

At $48 \mathrm{hpf}$, the effect of TBBPA $(1,10$ and $100 \mu \mathrm{g} / \mathrm{L})$ was evaluated by scoring larval phenotypes in at least 50 larvae/sample. A larva was considered normal when the shell was D-shaped (straight hinge) and the mantle did not protrude out of the shell, and malformed if the larva had not reached the stage typical for $48 \mathrm{~h}$ (trocophore or earlier stages) or when developmental defects were observed (concave, malformed or damaged shell, protruding mantle) (Fabbri et al., 2014). Data are reported as $\%$ values of normal D-veligers. The acceptability of test results was based on control samples with a percentage of normal D-larvae $>75 \%$ (ASTM, 2012).

The time-course of shell formation was also investigated at different times pf between the trochophora and the D-veliger stage (24, 28, 32 and $48 \mathrm{hpf})$. Larval shell components were visualized by Calcofluor White Fluorescent Brightener 28 (Sigma Aldrich, Lyon, France) for organic matrix, and Calcein (Sigma Aldrich, Lyon, France) for $\mathrm{CaCO}_{3}$ deposition, respectively (Miglioli et al., 2019, 2021a). Larvae were imaged with a Leica SP8 Confocal Laser Scanning Microscope (CLSM - Leica, France) scanning sequentially Brightfield, Calcofluor, and Calcein signals with a $0.5 \mu \mathrm{m} \mathrm{Z}$-stack interval. Channels were merged, 3D rendered and rotated to measure the area (in $\mu \mathrm{m}^{2}$ ) of each shell component in a single valva of each larva by manual drawing using IMAGEJ software (Miglioli et al., 2019, 2021a). Analyses were performed on at least 50 larvae for each sample. Data were normalized with respect to controls for each parental pair and experimental condition.

\subsection{Role of thyroid hormone and dopamine signaling in early larval development}


The role of thyroid hormone-TH and dopamine signaling were investigated by exposure of fertilized eggs to different $\mathrm{TH}$ agonists and antagonist: Triiodotyronine $\left(\mathrm{T}_{3}\right)$ and Tetraiodotyronine $\left(\mathrm{T}_{4}\right)$, the selective and high-affinity THR antagonist 1-850 (Schapira et al., 2003), and the antithyroid drug thiourea (TU), a TH depleting compound (Davidson et al., 1979) and to the selective antagonist of dopamine receptor DR1, SCH 23390 (Liu et al., 2018, 2020) (See SI).

\subsection{Scanning electron microscopy (SEM) of larval shell}

Control and TBBPA exposed larvae $(1$ and $10 \mu \mathrm{g} / \mathrm{L})$ at $48 \mathrm{hpf}$ were fixed in $3 \%$ glutaraldehyde in ASW. After fixation, samples were placed onto Whatman $22 \mu \mathrm{m}$ filters, dehydrated in an ascending ethanol series (50\% - 80\% - 90\% - 100\%) and air-dried. Samples were sputter-coated with gold and observed at $20 \mathrm{kV}$ with a Vega3 - Tescan scanning electron microscope. All procedures were carried out as previously described (Balbi et al., 2016, 2017, 2018).

\section{$2.5 q P C R$}

Fertilized eggs were exposed to TBBPA (10 $\mathrm{g} / \mathrm{L})$ in polystyrene 6-well plates (Balbi et al., 2016; Miglioli et al., 2021a). Control samples were run in parallel. Larvae were collected at 24, 28, 32 and $48 \mathrm{hpf}$ by a nylon mesh ( $20 \mu \mathrm{m}$ pore-filter) and washed with filter sterilized artificial seawater (ASW) (Balbi et al., 2016). Three wells for each sample were pooled in order to obtain approximately 7000 larvae/replicate. All procedures (RNA extraction, retro-transcription and qPCR) were carried out as previously described (Balbi et al., 2016; Miglioli et al., 2019, 2021a). Primers utilized for qPCR are reported in Tab. S1.

\subsection{In Situ Hybridization}

In situ hybridization (ISH) was used to evaluate the expression pattern of enzymes involved in matrix deposition (tyrosinase and chitinase) and of components of the dopaminergic system (Tyrosine Hydroxylase, Dopamine- $\beta$-Hydroxylase, Dopamine Receptor 1-DR1) following the protocol 
developed for M. galloprovincialis larvae (Miglioli et al., 2019, 2021a). Primer pairs were designed to amplify approximately $1-1.5 \mathrm{~Kb}$ cDNA fragment of mussel Tyrosinase (F: ATGCGATTCTTtATACATGAAA; R: TTGGTGGTTTGGTACATGT; GeneBank KV583276.1); Chitinase (F: CACCATGAATCTTAGAGGGATACAC; R: TGAACATCCGGGTACATTATA; GeneBank KP757835.1); Tyrosine Hydroxylase (F: ATGTATTCACCGACACCTCG; $\quad$ R: ACACCTTCAGTTCTTTTACTG; $\quad$ GeneBank GGUW01014444.1); Dopamine- $\beta$-Hydroxylase (F: CCTTCTGAAGTTTGCCTTTTC; R: CTGGCTCCCCGGGCACT; GeneBank GHIK01112718.1); Dopamine Receptor 1-DR1 (F: ATGATAACAAATTTTTCTATATTGG; R: ACAAAGCAGTTACCTTGTCCT; GeneBank Unigene27870_All). Amplicons were used to synthesize sense and antisense digoxigenin-labelled RNA probes (Miglioli et al., 2019, 2021a). Control and TBBPA-exposed larvae (10 $\mu \mathrm{g} / \mathrm{L})$ were grown in $50 \mathrm{~mL}$ culture flasks as described above, sampled at 24, 28, 32 and $48 \mathrm{hpf}$, concentrated with a 60 $\mu \mathrm{m}$ nylon filter, fixed overnight in $4 \%$ Paraformaldehyde in PBS, washed in the same buffer and kept in $100 \%$ methanol at $-20^{\circ} \mathrm{C}$. Analyses were performed on larvae from 4 independent parental pairs $(\mathrm{N}=4)$ (at least 50 individuals were analyzed for each sample).

\subsection{5-HT and GABA immunocytochemistry}

Antibodies against the neurotransmitter serotonin (5-HT) and $\gamma$-Aminobutyric acid (GABA) were utilized to visualize the development of the serotonergic and GABAergic systems in both control and TBBPA-exposed larvae $(10 \mu \mathrm{g} / \mathrm{L})$ at different times pf as previously described (Miglioli et al., 2021a; Vaasjo et al., 2018).

Samples were incubated with primary antibodies either against Rabbit 5-HT (1:10.000; Immunostar, Hudson, WI, USA) or GABA (1:4.000; A2052, Sigma Aldrich) for 5 days at $4^{\circ} \mathrm{C}$. Subsequently, samples were incubated with Anti-Rabbit Rhodamine Red ${ }^{\mathrm{TM}}-\mathrm{X}$ (RRX) IgG secondary antibody (1:500, Ex/Em: 570/590 nm - Jackson laboratory, Bar Harbor, Maine, USA) for 3 days at $4^{\circ} \mathrm{C}$; nonspecific binding was evaluated in subsamples incubated only in the presence of the secondary 
antibody (not shown) as previously described (Miglioli et al., 2021a). Larvae were then stained with $1 \mu \mathrm{g} / \mathrm{mL}$ Hoechst in PBS (UV, Ex/Em: 352/461 nm- Hoechst 33342, Invitrogen) and mounted with glycerol phosphate buffered solution containing antifading agent (CitiFluorTM AF1, pH 10, Agar scientific). Samples were imaged with a Leica Sp8 CLSM. Hoechst, 5-HT immunoreactivity and Brightfield signals were sequentially scanned with a $0.3 \mu \mathrm{m}$ Z-stack interval. Using ImageJ software, channels were merged and subsequent Z-stacks were assembled in order to assess the number of 5HT-ir (immuno-reactive) cells as previously described (Miglioli et al., 2021a). Larvae stained with GABA Abs were entirely imaged in $0.6 \mu \mathrm{m}$ Z-stacks for a total of $100 \mathrm{z}$ planes, with Z-projections made with 10 sequential z planes (from z10 to z100). At least 50 individuals were analyzed for each sample and experimental condition $(\mathrm{N}=5)$.

\subsection{Statistics}

Data obtained from 4 or 5 independent parental pairs, depending on the experiment (mean \pm SD) were analysed by one-way nonparametric ANOVA (Kruskal-Wallis test) followed by the Tukey's test ( $\mathrm{p}<0.05)$ using GraphPad Prism 5 software (GraphPad Inc.).

\section{Results}

\subsection{Phenotypic changes induced by TBBPA in mussel larvae at $48 \mathrm{hpf}$}

The phenotypic effects of TBBPA were first evaluated in $48 \mathrm{hpf}$ larvae and the results are reported in Fig. 1. TBBPA induced a concentration-dependent decrease in the percentage of normal D-veligers as previously described (Fabbri et al., 2014) (Fig. 1A). At all concentrations, immature larvae (preveligers), as well as larvae withheld at the trocophora stage were observed, together with shell malformations. These effects could be better appreciated by Calcofluor/Calcein double staining, that shows deposition of each shell component, the organic matrix (blue) and $\mathrm{CaCO}_{3}$ (green) (Fig. 1B). The shell of normal D-veligers showed extensive calcification, accretion rings and straight hinge. In TBBPA-exposed samples $(10 \mu \mathrm{g} / \mathrm{L})$, malformed larvae were characterized by irregular calcification 
and hinge malformations; immature D-veligers were identified by incomplete calcification and protrusion of the velum, the larval feeding organ; other larvae showed the arrested trocophora phenotype (Fig. 1B).

The effects of TBBPA (10 and $1 \mu \mathrm{g} / \mathrm{L})$ on larval shells were investigated in more detail by SEM, and representative images are reported in Fig. 2 and 3, respectively. As previously described (Balbi et al., 2016, 2017, 2018) normal D-veliger shells were characterized by a straight hinge, symmetric valvae and a uniform, smooth surface (Fig. 2A, Fig. 3A). In TBBPA-exposed larvae (10 $\mu \mathrm{g} / \mathrm{L})$ shells showed irregular surfaces, holes, convex hinges, and fractures (Fig. 2B-E) often perpendicular to the hinge axis (Fig. 2F). At lower concentrations $(1 \mu \mathrm{g} / \mathrm{L})$ in addition to shell fractures (Fig. 3B), immature shells, characterized by polygonal shapes, asymmetric valvae (Fig. 3C, D) and protruding velum (Fig. 3E) were observed. Irregular calcification at the center of shell was also detected (Fig. 3F).

\subsection{Effects of TBBPA on shell formation at earlier larval stages}

The effects of TBBPA were further investigated by Calcofluor/Calcein staining at shorter times postfertilization $(24,28$, and $32 \mathrm{hpf})$, and the results are shown in Fig. 4. In Fig. 5, quantification of areas of occupied by the organic matrix and calcified shell in different experimental conditions are reported. In control larvae, at $24 \mathrm{hpf}$ (the trocophora stage) the initial shell was only made of organic matrix (blue) and characterized by a saddle shape (the shell field); calcification (green) was detectable from $28 \mathrm{hpf}$, starting from the center of each valva, and increased at $32 \mathrm{hpf}$, with evident shell accretion rings, whereas the hinge region was not calcified yet. Complete calcification, including the hinge, was observed at $48 \mathrm{hpf}$ (Fig. 4). Exposure to TBBPA (10 $\mathrm{gg} / \mathrm{L})$ induced a significant decrease in the calcified shell area from $28 \mathrm{hpf}$, and in matrix deposition at $32 \mathrm{hpf}$ (Fig. 4 and Fig. 5B, C). Interestingly, in TBBPA-exposed larvae, absence of calcification was observed in the center of the valvae from 28 to $48 \mathrm{hpf}$ (Fig. 4), corresponding to the irregular shell calcification observed by SEM in some individuals at $48 \mathrm{hpf}$. Overall, TBBPA $(10 \mu \mathrm{g} / \mathrm{L})$ induced a significant increase in the ratio organic matrix/calcified shell at $28 \mathrm{hpf}$ (Fig. 5D). Stronger effects were observed at higher 
concentrations (100 $\mu \mathrm{g} / \mathrm{L})$ (Fig. 4 and Fig. 5A-D). All the following experiments were performed at $10 \mu \mathrm{g} / \mathrm{L}$ TBBPA.

\subsection{Effects of TBBPA on transcription of genes involved in early shell formation}

Transcription of selected genes involved in first shell formation (Miglioli et al., 2019) was evaluated by qPCR in larvae exposed to TBBPA $(10 \mu \mathrm{g} / \mathrm{L})$ at different times pf. In Fig. 6 data are reported on changes in mRNA level for genes involved in matrix deposition and remodeling (chitin synthase-CS; tyrosinase-TYR) and calcification (carbonic anhydrase-CA; extrapallial protein-EP) in control and TBBPA-exposed samples across different stages with respect to eggs. Transcription of CS was upregulated at 32 and $48 \mathrm{hpf}$ in control samples, and TBBPA induced a further small but significant increase at $48 \mathrm{hpf}(+20 \%$ with respect to controls) (Fig. 6A). Although basal expression of TYR in control larvae is very high with respect to eggs at all times pf (Miglioli et al., 2019, 2021a), TBBPA induced a further general upregulation at all stages, that was highest at both 28 and 48 hpf (+85\% vs controls, p<0.05) (Fig. 6B). Transcription of CA was unaffected by TBBPA (Fig. 6C); however, TBBPA induced a general increase in mRNA levels for EP, with highest upregulation at 28 and 48 hpf (+105 and $+135 \%$ vs controls, respectively, p<0.05) (Fig. 6D).

The expression pattern of tyrosinase and of chitinase, the enzyme involved in degradation of chitin, the main component of the organic matrix, was also investigated by ISH, and the results are reported in Fig. 7. As previously demonstrated (Miglioli et al., 2021a), tyrosinase was strongly expressed at all time pf in the areas corresponding to the organic matrix of the growing shell. TBBPA exposure resulted in a general upregulation of tyrosinase, in line with the results obtained by PCR, without significantly affecting its localization. Chitinase showed expression in the central part of the shell in larvae from 24 to $32 \mathrm{hpf}$, followed by a sharp decrease in expression in D-veligers. TBBPA did not affect chitinase localization at 24 and $28 \mathrm{hpf}$, whereas it induced some downregulation at $32 \mathrm{hpf}$ and some upregulation at 48 hpf (Fig. 7). 
3.4 Role of thyroid and dopamine signaling in mussel shell morphogenesis as possible targets of

\section{TBBPA}

Since in vertebrate developmental models, including the zebrafish, TBBPA mainly affects thyroid hormone signalling (Zhu et al., 2018 and refs. therein; Yu et al., 2021) the role of this pathway was first investigated by exposure of fertilized eggs to the thyroid Receptor-THR agonists Triiodotyronine $\left(\mathrm{T}_{3}\right)$ and Tetraiodotyronine $\left(\mathrm{T}_{4}\right)$, the THR antagonist 1-850, and the antithyroid drug thiourea (TU). None of these compounds significantly affected larval development at $48 \mathrm{hpf}$, in terms of changes in proportion of larval phenotypes (Fig. S1). Only the THR antagonist 1-850 induced a slight decrease in the percentage of normal D-veligers; however, the values were above the acceptability of the test results (>75\% normal larvae) (ASTM, 2012). The results indicate that thyroid hormone signalling does not play a key role in shell morphogenesis in mussel early larval stages.

In analogy with data obtained in oysters (Liu et al., 2018, 2020), the possible involvement of the dopaminergic system in mussel larval development was investigated. Exposure to the DR1 antagonist SCH 23390 resulted in a complete disruption of shell formation. In particular, no calcification was observed up to $32 \mathrm{hpf}$ (Fig. S2) and, from 24 to $32 \mathrm{hpf}$, the area of the shell field occupied by the organic matrix was reduced to less than $20 \%$ of controls (Fig. S2B). At 48 hpf, a severe impairment of calcification was observed (Fig. S2B), the overall effects resulting in about an $80 \%$ decrease in the percentage of normal D-larvae (Fig. S2C).

\subsection{TBBPA affects the expression pattern of dopaminergic components}

The effects of TBBPA $(10 \mu \mathrm{g} / \mathrm{L})$ on key components of the dopaminergic system were then investigated. To this aim, expression pattern of key enzymes involved in DOPA synthesis (Tyrosine Hydroxylase) and metabolism (Dopamine- $\beta$-Hydroxylase) and of the DOPA receptor DR1 were evaluated by ISH, and the results are shown in Fig. 8. Exposure to TBBPA induced changes in the expression pattern of all genes from $24 \mathrm{hpf}$. In control larvae, the dopaminergic marker $\mathrm{TH}$, responsible for the synthesis of DOPA from the amino acid tyrosine, showed a diffuse localization at 
$24 \mathrm{hpf}$, followed by progressive concentration in two clusters dopaminergic neurons at $28 \mathrm{hpf}$ and 32 hpf; at 48 hpf, a clear localization of TH in a single cluster was observed. TBBPA-exposed larvae showed a stronger and more diffuse signal at earlier stages, with two observable clusters remaining at $48 \mathrm{hpf}$ (suggesting a delay in the differentiation of dopaminergic cell ganglion). Expression of D $\beta \mathrm{H}$ (the enzyme that catalyzes the conversion of DOPA to noradrenaline) was detectable in control samples from $28 \mathrm{hpf}$ at the center of the larval body and showed a distinct localization only at $48 \mathrm{hpf}$. TBBPA resulted in a general upregulation of $\mathrm{D} \beta \mathrm{H}$ at all times pf, except for at $28 \mathrm{hpf}$. DR1 in control larvae showed a weak expression in the trocophorae at $24 \mathrm{hpf}$ and subsequently increased during transition to the D-veliger, showing a sharp localization along the margins of the growing shell. In TBBPA-exposed larvae, DR1 was not expressed at $24 \mathrm{hpf}$; a weaker signal and less distinct localization were observed from 28 to $32 \mathrm{hpf}$, followed by strong upregulation at $48 \mathrm{hpf}$.

\subsection{TBBPA affects serotonin and GABA immunoreactivity}

Development of serotonin immunopositive cells (5-HT-ir), a key step in early mussel larvae neurodevelopment, was evaluated by immunocytochemistry as previously described (Miglioli et al., 2021a), and the results are reported in Fig. 9 and Fig. 10. In control larvae, the number of 5-HT-ir cells progressively increased from 2 to 7 from 24 to 48 hpf (Fig. 9A and Fig. 10A) as previously reported (Miglioli et al. 2021a). In samples exposed to TBBPA $(10 \mu \mathrm{g} / \mathrm{L})$, the 5-HT positive ganglion was still present: however, the number of 5-HT-ir neurons was generally lower at all times pf (Fig. 9B and Fig. 10B). In particular, at 48 hpf, such a decrease, was clearly evident in immature veligers and arrested trocophorae (Fig. 10B), and statistically significant in all treated larvae with respect to controls (Fig. 11). However, TBBPA did not affect mRNA levels for the serotonin receptor 5-HTR at any time pf (not shown).

Development of GABA-ir cells was also evaluated from 24 to 48 hpf (Fig. 12 and Fig. 13). Due to strong GABA signal observed at all times pf, larvae were entirely imaged in $100 \mathrm{z}$-stacks, with Zprojections made every 10 sequential stacks (from z10 to z100) to better identify the localization of 
GABA-ir cells (Fig S3 and S4). In control larvae, several GABA-ir cells were detected at 24 and 28 hpf, along the shell field and at the center of the body (Fig. 12A and Fig S3). From 32 hpf, immunoreactivity was concentrated along the external margins of the larvae. In TBBPA-exposed samples $(10 \mu \mathrm{g} / \mathrm{L})$, a clear decrease in the GABA signal was observed from 24 to 32 hpf (Fig. 12B). At $48 \mathrm{hpf}$, GABA immunoreactivity was concentrated along the external margin of the body in control samples (Fig. 13A and Fig. S4). At this stage, in samples exposed to $10 \mu \mathrm{g} / \mathrm{L}$ TBBPA, GABAir cells were localized in the protruding velum of immature veligers (pre-veligers), and arrested trocophores showed the strong immunoreactivity observed in control 24-28 hpf trocophores (Fig. 13B).

\section{Discussion}

The results here obtained extend previous observations indicating that TBBPA interferes with early larval development of M. galloprovincialis (Fabbri et al., 2014) at concentrations encompassing those detectable in contaminated coastal areas (Gong et al., 2017 and refs. therein). Moreover, we provide first information on the mechanisms of action of TBBPA on mussel shell biogenesis and neurodevelopment from earlier larval stages. The effects of TBBPA on all endpoints measured from molecular to individual level were observed at $10 \mu \mathrm{g} / \mathrm{L}$, a concentration of the same order of magnitude as those detected in polluted environments (low $\mu \mathrm{g} / \mathrm{L}$ ) (Liu et al., 2016; Gong et al., 2017 and refs. therein; Li et al., 2020).

TBBPA has been reported as a potential thyroid endocrine disruptor and neurotoxicant in mammalian and fish (i.e. the zebrafish) models through multiple mechanisms, indicating that particular attention should be paid to the effects of this compound on early developmental stages (reviewed in Zhou et al., 2020). In marine organisms, the effects of TBBPA have been investigated in a range of species across different trophic levels, indicating that some fish and molluscs are particularly sensitive to TBBPA (Pittinger and Pecquet, 2018; Nos et al., 2020). With regards to marine bivalves, acute exposure of the Eastern oyster Crassostrea virginica to TBBPA $(18 \mu \mathrm{g} / \mathrm{L}, 96 \mathrm{~h})$ significantly reduced 
shell growth (Springborn Life Sciences, 1989). In Mytilus edulis, chronic exposure (70 days) to TBBPA affected growth, with NOEC and LOEC values of 17 and $32 \mu \mathrm{g} / \mathrm{L}$, respectively (AstraZeneca, 2005a,b). In juveniles of the clam Ruditapes phillipinarum exposed to TBBPA (62.5 $1000 \mu \mathrm{g} / \mathrm{L}, 28$ days) inhibition of shell growth and filtration rate were observed (Jiang et al., 2019). Overall, these data indicates that shell growth represents a target for TBBPA in adult and juvenile bivalves, although at higher concentrations than those detected in the environment.

In M. galloprovincialis, TBBPA in a wide concentration range, encompassing environmental exposure levels (from ng to $\mu \mathrm{g} / \mathrm{L}$ ), affected early larval development, increasing the percentage of trocophorae/immature D-veligers (Fabbri et al., 2014). However, the possible mechanisms of action were not investigated, due to little information available on the molecular pathways regulating shell biogenesis in mussels. Subsequent studies shed some light on the expression pattern of genes involved in shell formation, and in neuroendocrine pathways in early mussel larvae grown both in physiological conditions and in the presence of different emerging contaminants (Balbi et al., 2016, 2017, 2018; Franzellitti et al., 2019; Miglioli et al., 2019, 2021a).

The results here presented provide information on the mechanisms of action of TBBPA in developing larvae across different stages, focusing on shell morphogenesis and neurogenesis. For a mechanistic study, all experiments were carried out at $10 \mu \mathrm{g} / \mathrm{L}$, a concentration about two-fold higher than both the $\mathrm{EC}_{50}$ obtained in the $48 \mathrm{~h}$ standard larval assay and TBBPA levels detected in polluted coastal areas. The utilization of calcein/calcofluor staining to visualize and quantify the deposition of each shell component, clearly demonstrated that TBBPA significantly increased the ratio organic matrix/calcified shell at $28 \mathrm{hpf}$, when the first calcification of the growing shell occurs (Miglioli et al., 2019), indicating a perturbation of the firsts steps of shell biogenesis. Moreover, TBBPA affected the pattern of calcification; in particular, no $\mathrm{CaCO}_{3}$ deposition at the center of the valvae was observed, resulting in a 'key hole' phenotype similar to that previously observed in mussel larvae exposed to acidification (Kapsenberg et al., 2018). These data indicate that TBBPA affects the mechanisms involved in deposition of the organic matrix, which represents the blueprint for 
biomineralization and normal shell biogenesis. The effects of TBBPA on shell formation could be appreciated by SEM imaging at $48 \mathrm{hpf}$, at concentrations as low as $1 \mu \mathrm{g} / \mathrm{L}$, confirming delayed development and irregular calcification.

Data on gene expression offer a first glimpse into the underlying mechanisms of TBBPA on shell formation, indicating a general dysregulation of the expression pattern of genes involved in matrix deposition and calcification across different developmental stages, with tyrosinase representing the most upregulated gene from $28 \mathrm{hpf}$. Tyrosinase has been identified as a key enzyme in organic matrix remodeling in early mussel larvae grown in physiological conditions (Miglioli et al., 2019), as well as a target of BPA (Miglioli et al., 2021a). The results here obtained indicate that TBBPA induced a stronger upregulation of tyrosinase with respect to BPA at similar concentrations (10 vs $11.4 \mu \mathrm{g} / \mathrm{L})$ at all stages pf (Miglioli et al., 2021a); the effects were also stronger when compared on a molar basis (18 nM TBBPA vs $50 \mathrm{nM}$ BPA). TBBPA also resulted in upregulation of EP, that plays a key role in calcification, with a similar trend across different stages. Only at $48 \mathrm{hpf}$, increased expression of chitin synthase and decreased that of chitinase were observed, as shown by both qPCR and ISH. These results indicate that increased synthesis of chitin, the main component of the shell organic matrix, typical of the initial stages of shell deposition, is upregulated by TBBPA at later stages, further supporting a delay in development. Overall, these data partly contribute to explain the phenotypic effects of TBBPA on shell formation.

BPA has been previously shown to affect expression of genes involved in detoxification response in mussel larvae (Balbi et al., 2016). However, TBBPA (up to $10 \mu \mathrm{g} / \mathrm{L}$ ) did not induce changes in mRNA levels for glutathione-s-transferase (GST $\pi$ ) and the ABC transporter p-glycoprotein (ABCB) with respect to controls at any developmental stage (not shown), suggesting that mussel early larvae have little capacity for TBBPA biotransformation/detoxification.

The possible endocrine mechanisms of action of TBBPA were then investigated. In vertebrate systems TBBPA, structurally resembling thyroid hormones, can act as an endocrine disruptor affecting TH signaling and metabolism (Zhang et al., 2014; Zhou et al., 2020). These mechanisms 
have been shown to be associated with the neurodevelopmental toxicity of TBBPA in the zebrafish embryo (Zhu et al., 2018; Pang et al., 2020; Yu et al., 2021). The presence of THs and related signaling components has been demonstrated in developing and adult bivalves (Huang et al., 2015; Taylor and Heyland, 2017; Miglioli et al., 2021b). In clam juveniles, prolonged exposure to TBBPA caused alterations in tissue content of THs and in expression of TH synthesis-related enzymes (Jiang et al., 2019). In the oyster $C$. gigas, TH signaling was shown to be involved in embryogenesis and metamorphosis; however, from the trocophora to the first $\mathrm{D}$-veliger stage, lowest values of $\mathrm{T}_{3}$ and $\mathrm{T}_{4}$ and absence of THR expression were observed (Huang et al., 2015). Accordingly, the results here obtained with M. galloprovincialis show that exposure to different TH agonists and antagonists did not affect larval development at $48 \mathrm{hpf}$. These observations support the hypothesis that TH signaling, which is considered a common target for the endocrine effects of TBBPA also in aquatic species, does not represent a key pathway in the transition from the trocophora and the first D-veliger of bivalve larvae. Therefore, other mechanisms may be involved in the action of TBBPA as a potential developmental disruptor in early developmental stages of mussel larvae.

Neuroendocrine mechanisms are known to play a vital role in larval development of invertebrates (Cann-Moisan et al., 2002). Molecular components of the neuroendocrine system have been characterized in marine bivalves (catecholaminergic, cholinergic, enkephalinergic, serotoninergic, gamma-aminobutyric acid-ergic, and neuropeptide systems), and they share a similar molecular basis with their vertebrate counterparts (Wang et al., 2018; Liu et al., 2018; Joyce and Vogeler, 2018). In larvae of the oyster $C$. gigas, expression of a DOPA receptor Cg-DR-1 peaked during the transition from the trocophora to the D-veliger stage, indicating a role in shell biogenesis (Liu et al., 2018). In a subsequent study, exposure of trocophorae to DR1 and 5-HTR inhibitors was found to prevent shell formation (Liu et al., 2020). Metabolomic and transcriptomic analyses suggested that the synthesis of DOPA and 5-HT may modulate initial shell formation through the TGF- $\beta$ smad pathway, by activating the expression of tyrosinase and chitinase, that are essential for initial shell biogenesis (Liu et al., 2020). 
The results here presented extend the findings in oysters by showing that in M. galloprovincialis, exposure of fertilized eggs to the selective DR1 inhibitor SCH 23390 disrupted shell formation at a concentration 20 times lower than those utilized in oyster trocophorae (Liu et al., 2020). Therefore, DOPA signaling has a key role in mussel shell morphogenesis. TBBPA induced alterations in the expression pattern of enzymes involved in DOPA synthesis and metabolism and of the DOPA receptor DR1 from $24 \mathrm{hpf}$, indicating a delay in the differentiation of dopaminergic neurons and DR1 expression, as well as an increased metabolism of DOPA. The effects on the dopaminergic system were detectable before the changes in expression of shell related genes observed from $28 \mathrm{hpf}$. We hypothesize that impairment of dopamine system interferes with the initial processes of shell deposition, resulting in altered shell phenotypes and delayed development. Only at later stages (48 hpf), TBBPA-induced upregulation of DR1 was accompanied by increased expression of tyrosinase, chitin synthase, EP, whereas chitinase was downregulated. Another link between dopaminergic signaling and shell formation is suggested by the results obtained on expression of mussel EP protein, that is involved in controlling the deposition of $\mathrm{CaCO}_{3}$ polymorphs, including vaterite, the most unstable crystalline phase formed during initial biomineralization (Ji et al., 2010). In the pearl mussel Hyriopsis cumingii DOPA has been involved in stability of vaterite (Kim and Park, 2010).

Serotonin represents a key navigational cue during bivalve neurodevelopment (Yurchenko et al., 2019) and shell formation (Liu et al., 2020). In M. galloprovincialis, BPA affected expression of tyrosinase, larval patterning and 5-HT signalling (Miglioli et al., 2021a). The results here presented show that also exposure to TBBPA impairs the development of serotoninergic neurons from $24 \mathrm{hpf}$, whose number was decreased in $48 \mathrm{hpf}$ larvae, characterized by delayed development and arrested phenotypes. Overall, the results indicate that tyrosinase, that represents a link between monoamine neurotransmitter signaling and shell biogenesis in both oysters and mussels (Liu et al., 2020; Miglioli et al., 2019, 2021a), is a potential target for endocrine disruptors in early bivalve development.

Finally, TBBPA showed dramatic effects on the development of GABA-ir cells in mussel larvae at early stages (24 hpf). In mammalian cells, TBBPA and other brominated flame retardants inhibited 
uptake of GABA and 5-HT (Mariussen and Fonnum, 2003). GABA is a conserved neurotransmitter in different phyla (Miller, 2019; Smart and Stephenson, 2019): in molluscs, GABA has been shown to affect larval settlement and metamorphosis, with possible downstream effects on serotonin pathways (Biscocho et al., 2018; Joyce and Vogeler, 2018, and refs therein). The high abundance of GABA-ir cells observed in control mussel trocophorae (at $24 \mathrm{hpf}$ ) is in line with the role of this neurotransmitter in the early developing mammalian brain, where the GABAergic system plays an important trophic role, even prior to synaptogenesis, in the proliferation of neuronal progenitor cells (reviewed in Wu and Sun, 2016). Overall, on the basis of our first observations, the dramatic decrease in GABA immunoreactivity induced by TBBPA further suggests that, in mussel larvae, TBBPA may act upstream of the first stages of neurodevelopment, to affect subsequent differentiation of serotoninergic or other neurons. Interference with GABA signalling has been involved in TBBPA neurotoxicity in Xenopus and zebrafish embryos (Hendriks et al., 2012; Ye et al., 2016). However, irrespective of the mechanisms of action, in vertebrate developmental models significant effects of TBBPA were observed from concentrations generally higher than those utilized in the present study; this further emphasize the sensitivity of mussel early larval stages towards TBBPA.

\section{Conclusions}

The results demonstrate that TBBPA affected components of DOPA, 5-HT and GABA systems in mussel larvae from $24 \mathrm{hpf}$; from $28 \mathrm{hpf}$, these effects were accompanied by changes in deposition of organic matrix and calcification of the growing shell, and altered transcription pattern of genes crucial for shell formation. The overall effects of TBBPA resulted in larval malformations and delayed/arrested development at $48 \mathrm{hpf}$. Although for a mechanistic study all the endpoints were evaluated at a concentration two-fold higher than those detected in polluted coastal areas, to our knowledge, these results represent the demonstration of the effects of TBBPA at the lowest concentrations tested so far in bivalves. 
The signaling pathways linking development of neurotransmitters with shell formation still need to be elucidated; however, the data obtained so far (this work, Miglioli et al., 2021a) indicate that EDs such as TBBPA and BPA can affect the complex processes involved in early neurodevelopment and shell biogenesis in the model marine bivalve Mytilus.

The identification of the mode of action (MOA) of EDs in marine invertebrates can contribute building Adverse outcome pathways (AOPs) (Ankley et al., 2010; Ford and Le Blanc, 2020), encompassing relationships from molecular initiating events (MIE) caused by the initial exposure, to a series of key events (KE), that lead to identification of effects on individuals (i.e. developmental effects) and potential loss of population sustainability. Although the possible consequences of TBBPA at the population level cannot at present be demonstrated, the results of this work provide data on possible progression of the effects of this compound from the molecular to the individual level.

A better understanding of the neuroendocrine function during development in model marine invertebrates will greatly help understanding the impact of emerging pollutants, in particular EDs, as well as of other environmental stressors, on more susceptible life stages of ecologically important species in coastal environments.

\section{CRediT authorship contribution statement}

Angelica Miglioli: Investigation, Methodology, Data curation, Writing. Teresa Balbi: Investigation, Data curation, methodology, Writing, review \& editing, funding acquisition. Michele Montagna: data curation, methodology. Remi Dumollard: Conceptualization, Supervision, Writing, funding acquisition. Laura Canesi: Conceptualization, Supervision, Writing.

\section{Declaration of Competing Interest}

The authors declare that they have no known competing financial interests or personal relationships that could have appeared to influence the work reported in this paper. 


\section{Acknowledgments}

507 The authors would like to thank Laurent Gilletta, Alexandre Jean, Régis Lasbleiz and the Centre de 508 Ressources Biologiques Marines of the CRBM-IMEV that is supported by EMBRC-France, whose 509 French state funds are managed by the Agence Nationale de la Recherche (ANR) within the 510 'Investissement d'Avenir' program (ANR-10-INBS-02); Sameh Benaicha; the Ascidian BioCell 511 group members.

512 This work was partially supported by an ANR grant (Marine-EmbryoTox project, ANR-14-OHRI-

513 0009-01-1, R. Dumollard), ad by Fondi di Ricerca di Ateneo, FRA2020, University of Genoa (T. 514 Balbi). 
1. Ankley, G.T., Bennett, R.S., Erickson, R.J., Hoff, D.J., Hornung, M.W., Johnson, R.D., Mount, D.R., Nichols, J.W., Russom, C.L., Schmieder, P.K., Serrano, J.A., Tietge, J.E., Villeneuve, D.L., 2010. Adverse outcome pathways: a conceptual framework to support https://doi.org/10.1002/etc.34

2. ASTM, 2012. Standard guide for conducting static acute toxicity tests starting with embryos of four species of saltwater bivalve molluscs. https://doi.org/10.1520/E0724-98R12

3. AstraZeneca, 2005a. TBBPA: determination of effects on the growth of the common mussel Mytilus edulis. AstraZeneca UK Limited. Brixham Environmental Laboratory Study Number: 03-0337/A

4. AstraZeneca, 2005b. Tetrabromobisphenol A: determination of the effect on the growth of the common mussel (Mytilus edulis). Analytical phase. Wildlife International, Ltd. Project. Number: 439C-143

5. Balbi, T., Franzellitti, S., Fabbri, R., Montagna, M., Fabbri, E., Canesi, L., 2016. Impact of bisphenol A (BPA) on early embryo development in the marine mussel Mytilus galloprovincialis: Effects on gene transcription. Environ. Pollut. 218, 996-1004. https://doi.org/10.1016/j.envpol.2016.08.050

6. Balbi, T., Camisassi, G., Montagna, M., Fabbri, R., Franzellitti, S., Carbone, C., Dawson, K., Canesi, L., 2017. Impact of cationic polystyrene nanoparticles (PS-NH$)$ on early embryo development of Mytilus galloprovincialis: Effects on shell formation. Chemosphere 186, 1-9. https://doi.org/10.1016/j.chemosphere.2017.07.120

7. Balbi, T., Montagna, M., Fabbri, R., Carbone, C., Franzelllitti, S., Fabbri, E., Canesi, L., 2018. Diclofenac affects early embryo development in the marine bivalve Mytilus $\begin{array}{lllll}\text { galloprovincialis. } & \text { Sci. } & \text { Total } & \text { Environ. } & 642,\end{array}$ https://doi.org/10.1016/j.scitotenv.2018.06.125 
8. Biscocho, D., Cook, J.G., Long, J., Shah, N., Leise, E.M., 2018. GABA is an inhibitory neurotransmitter in the neural circuit regulating metamorphosis in a marine snail. Dev. Neurobiol. 78, 736-753. https://doi.org/10.1002/dneu.22597

9. Cann-Moisan, C., Nicolas, L., Robert, R., 2002. Ontogenic changes in the contents of dopamine, norepinephrine and serotonin in larvae and postlarvae of the bivalve Pecten maximus. Aquat. Living Resour. 15, 313-318. https://doi.org/10.1016/S09907440(02)01185-3

10. Covaci, A., Voorspoels, S., Abdallah, M.A., Geens, T., Harrad, S., Law, R.J., 2009. Analytical and environmental aspects of the flame retardant tetrabromobisphenol-A and its derivatives. J. Chromatogr. A 1216, 346-363. https://doi.org/10.1016/j.chroma.2008.08.035

11. Davidson, B., Soodak, M., Strout, H.V., Neary, J.T., Nakamura, C., Maloof, F., 1979. Thiourea and cyanamide as inhibitors of thyroid peroxidase: the role of iodide. Endocrinol. 104, 919-924. https://doi.org/10.1210/endo-104-4-919

12. Environmental Protection Agency-EPA 2019. https://www.epa.gov/assessing-and-

13. Fabbri, R., Montagna, M., Balbi, T., Raffo, E., Palumbo, F., Canesi, L., 2014. Adaptation of the bivalve embryotoxicity assay for the high throughput screening of emerging contaminants in Mytilus galloprovincialis. Mar. Environ. Res. 99, 1-8. https://doi.org/10.1016/j.marenvres.2014.05.007

14. Ford, A.T., LeBlanc, G.A., 2020. Endocrine disruption in invertebrates: A survey of research progress. Environ. Sci. Technol. 54, 13365-13369. https://doi.org/10.1021/acs.est.0c04226

15. Franzellitti, S., Balbi, T., Montagna, M., Fabbri, R., Valbonesi, P., Fabbri, E., Canesi, L., 2019. Phenotypical and molecular changes induced by carbamazepine and propranolol on 
larval stages of Mytilus galloprovincialis. Chemosphere 234, 962-970. https://doi.org/10.1016/j.chemosphere.2019.06.045

16. Gong, W.J., Zhu, L.Y., Jiang, T.T., Han, C., 2017. The occurrence and spatial-temporal distribution of tetrabromobisphenol A in the coastal intertidal zone of Qingdao in China, with a focus on toxicity assessment by biological monitoring. Chemosphere 185, 462-467. https://doi.org/10.1016/j.chemosphere.2017.07.033

17. Gu, C., Wang, J., Zhao, Z., Han, Y., Du, M., Zan, S., Wang, F., 2019. Aerobic cometabolism of tetrabromobisphenol A by marine bacterial consortia. Environ. Sci. Pollut. Res. Int. 26, 23832-23841. https://doi.org/10.1007/s11356-019-05660-7

18. Hendriks, H.S., van Kleef, R.G., van den Berg, M., Westerink, R.H., 2012. Multiple novel modes of action involved in the in vitro neurotoxic effects of tetrabromobisphenol-A. Toxicol. Sci. 128, 235-246. https://doi.org/10.1093/toxsci/kfs136

19. Huang, W., Xu, F., Qu, T., Zhang, R., Li, L., Que, H., Zhang, G., 2015. Identification of thyroid hormones and functional characterization of thyroid hormone receptor in the Pacific oyster Crassostrea gigas provide insight into evolution of the thyroid hormone system. PLoS One 10, e0144991. https://doi.org/10.1371/journal.pone.0144991

20. Ji, B., Cusack, M., Freer, A., Dobson, P.S., Gadegaard, N., Yin, H., 2010. Control of crystal polymorph in microfluidics using molluscan $28 \mathrm{kDa} \mathrm{Ca}^{2+}$-binding protein. Integr. Biol. 2, 528-535. https://doi.org/10.1039/c0ib00007h

21. Jiang, S., Miao, J., Wang, X., Liu, P., Pan, L, 2019. Inhibition of growth in juvenile manila clam Ruditapes philippinarum: Potential adverse outcome pathway of TBBPA. Chemosphere 224, 588-596. https://doi.org/10.1016/j.chemosphere.2019.02.157

22. Joyce, A., Vogeler, S., 2018. Molluscan bivalve settlement and metamorphosis: Neuroendocrine inducers and morphogenetic responses. Aquaculture 487, 64-82. https://doi.org/10.1016/j.aquaculture.2018.01.002 
23. Kapsenberg, L., Miglioli, A., Bitter, M.C., Tambutté, E., Dumollard, R., Gattuso, J.P., 2018. Ocean $\mathrm{pH}$ fluctuations affect mussel larvae at key developmental transitions. Proc. R. Soc. B. 285, 20182381. https://doi.org/10.1098/rspb.2018.2381

24. Kim, S., Park, C.B., 2010. Dopamine-induced mineralization of calcium carbonate vaterite microspheres. Langmuir 26, 14730-14736. https://doi.org/10.1021/la1027509

25. Li, Z., Pan, L., Guo, R., Cao, Y., Sun, J., 2020. A verification of correlation between chemical monitoring and multibiomarker approach using clam Ruditapes philippinarum and scallop Chlamys farreri to assess the impact of pollution in Shandong coastal area of China. Mar. Pollut. Bull. 155, 111155. https://doi.org/10.1016/j.marpolbul.2020.111155

26. Liu, K., Li, J., Yan, S.J., Zhang, W., Li, Y.J., Han, D., 2016. A review of status of tetrabromobisphenol A (TBBPA) in China. Chemosphere 148, 8-12. https://doi.org/10.1016/j.chemosphere.2016.01.023

27. Liu, Z., Wang, L., Yan, Y., Zheng, Y., Ge, W., Li, M., Wang, W., Song, X., Song, L., 2018. D1 dopamine receptor is involved in shell formation in larvae of Pacific oyster Crassostrea gigas. Dev. Comp. Immunol. 84, 337-342. https://doi.org/10.1016/j.dci.2018.03.009

28. Liu, Z., Zhou, Z., Zhang, Y., Wang, L., Song, X., Wang, W., Zheng, Y., Zong, Y., Lv, Z., Song, L., 2020. Ocean acidification inhibits initial shell formation of oyster larvae by suppressing the biosynthesis of serotonin and dopamine. Sci. Total Environ. 735, 139469. https://doi.org/10.1016/j.scitotenv.2020.139469

29. Mariussen, E., Fonnum, F., 2003. The effect of brominated flame retardants on neurotransmitter uptake into rat brain synaptosomes and vesicles. Neurochem. Int. 43, 533542. https://doi.org/10.1016/s0197-0186(03)00044-5

30. Miglioli, A., Dumollard, R., Balbi, T., Besnardeau, L., Canesi, L., 2019. Characterization of the main steps in first shell formation in Mytilus galloprovincialis: possible role of tyrosinase. Proc. R. Soc. B. 286, 20192043. https://doi.org/10.1098/rspb.2019.2043 
31. Miglioli, A., Balbi, T., Besnardeau, L., Dumollard, R., Canesi, L., 2021a. Bisphenol A interferes with first shell formation and development of the serotoninergic system in early larval stages of Mytilus galloprovincialis. Sci. Total Environ. 758, 144003. https://doi.org/10.1016/j.scitotenv.2020.144003

32. Miglioli, A., Canesi, L., Gomes, I.D.L., Schubert, M., Dumollard, R., 2021b. Nuclear receptors and development of marine invertebrates. Genes 12, 83. https://doi.org/10.3390/genes12010083

33. Miller, M.W., 2019. GABA as a neurotransmitter in gastropod molluscs. Biol. Bull. 236, 144-156. https://doi.org/10.1086/701377

34. Morris, S., Allchin, C.R., Zegers, B.N., Haftka, J.J., Boon, J.P., Belpaire, C., Leonards, P.E., Van Leeuwen, S.P., de Boer, J., 2004. Distribution and fate of HBCD and TBBPA brominated flame retardants in North Sea estuaries and aquatic food webs. Environ. Sci. Technol. 38, 5497-5504. https://doi.org/10.1021/es049640i

35. Nos, D., Navarro, J., Saiz, E., Sanchez-Hernandez, J.C., Solé, M., 2020. Tetrabromobisphenol A inhibits carboxylesterase activity of marine organisms from different trophic levels.

Chemosphere 238 , 124592. https://doi.org/10.1016/j.chemosphere.2019.124592

36. Pang, S., Gao, Y., Li, A., Yao, X., Qu, G., Hu, L., Liang, Y., Song, M., Jiang, G., 2020. Tetrabromobisphenol A perturbs erythropoiesis and impairs blood circulation in zebrafish embryos. Environ. Sci. Technol. 54, 12998-13007. https://doi.org/10.1021/acs.est.0c02934 37. Pittinger, C.A., Pecquet, A.M., 2018. Review of historical aquatic toxicity and bioconcentration data for the brominated flame retardant tetrabromobisphenol A (TBBPA): effects to fish, invertebrates, algae, and microbial communities. Environ. Sci. Pollut. Res. Int. 25, 14361-14372. https://doi.org/10.1007/s11356-018-1998-y

38. Schapira, M., Raaka, B.M., Das, S., Fan, L., Totrov, M., Zhou, Z., Wilson, S.R., Abagyan, R., Samuels, H.H., 2003. Discovery of diverse thyroid hormone receptor antagonists by 
high-throughput docking. Proc. Natl. Acad. Sci. USA 100, 7354-7359. https://doi.org/10.1073/pnas.1131854100

39. Shi, Z., Zhang, L., Zhao, Y., Sun, Z., Zhou, X., Li, J., Wu, Y., 2017. A national survey of tetrabromobisphenol-A, hexabromocyclododecane and decabrominated diphenyl ether in human milk from China: Occurrence and exposure assessment. Sci. Total Environ. 599600, 237-245. https://doi.org/10.1016/j.scitotenv.2017.04.237

40. Smart, T.G., Stephenson, F.A., 2019. A half century of $\gamma$-aminobutyric acid. Brain Neurosci. Adv. 3, 2398212819858249. https://doi.org/10.1177/2398212819858249

41. Springborn Life Sciences, 1989. Acute toxicity of tetrabromobisphenol A to eastern oysters (Crassostrea virginica) under flow-through conditions. Springborn Life Sciences, Inc. Report \#89-1-2898, Study \#1199-0688-6106-504

42. Sühring, R., Barber, J.L., Wolschke, H., Kötke, D., Ebinghaus, R., 2015. Fingerprint analysis of brominated flame retardants and Dechloranes in North Sea sediments. Environ. Res. 140, 569-578. https://doi.org/10.1016/j.envres.2015.05.018

43. Taylor, E., Heyland, A., 2017. Evolution of thyroid hormone signaling in animals: Nongenomic and genomic modes of action. Mol. Cell Endocrinol. 459, 14-20. https://doi.org/10.1016/j.mce.2017.05.019

44. Vaasjo, L.O., Quintana, A.M., Habib, M.R., Mendez de Jesus, P.A., Croll, R.P., Miller, M.W., 2018. GABA-like immunoreactivity in Biomphalaria: Colocalization with tyrosine hydroxylase-like immunoreactivity in the feeding motor systems of Panpulmonate snails. J. Comp. Neurol. 526, 1790-1805. https://doi.org/10.1002/cne.24448

45. Wang, X., Li, C., Yuan, X., Yang, S., 2020. Contamination level, distribution characteristics, and ecotoxicity of tetrabromobisphenol $\mathrm{A}$ in water and sediment from Weihe river basin, China. Int. J. Environ. Res. Public Health 17, 3750. https://doi.org/10.3390/ijerph17113750 
46. Wang, L., Song, X., Song, L., 2018. The oyster immunity. Dev. Comp. Immunol. 80, 99118. https://doi.org/10.1016/j.dci.2017.05.025

47. WorldAnalytics, 2019. Global Tetrabromobisphenol-A (TBBA) (CAS: 79-94-7) market competitive analysis, market size, share, consumption, production forecast 2019-2023. https://worldanalytics24.com/globaltetrabromobisphenol-a-tbba-cas-79-94-7market/236248

48. Wu, C., Sun, D., 2016. GABA receptors in brain development, function, and injury. Metab. Brain Dis. 30, 367-379. https://doi.org/10.1007/s11011-014-9560-1

49. Yang, S., Wang, S., Liu, H., Yan, Z., 2012. Tetrabromobisphenol A: tissue distribution in fish, and seasonal variation in water and sediment of Chaohu Lake, China. Environ. Sci. Pollut. Res. Int. 19, 4090-4096. https://doi.org/10.1007/s11356-012-1023-9

50. Ye, G., Chen, Y., Wang, H, Ye, T., Lin, Y., Huang, Q., Chi, Y., Dong, S., 2016. Metabolomics approach reveals metabolic disorders and potential biomarkers associated with the developmental toxicity of tetrabromobisphenol A and tetrachlorobisphenol A. Sci. Rep. 6, 35257. https://doi.org/10.1038/srep35257

51. Yurchenko, O.V., Savelieva, A.V., Kolotuchina, N.K., Voronezhskaya, E.E., Dyachuk, V.A., 2019. Peripheral sensory neurons govern development of the nervous system in bivalve larvae. EvoDevo. 10, 22. https://doi.org/10.1186/s13227-019-0133-6

52. Zhang, Y.F., Xu, W., Lou, Q.Q., Li, Y.Y., Zhao, Y.X., Wei, W.J., Qin, Z.F., Wang, H.L., Li, J.Z., 2014. Tetrabromobisphenol A disrupts vertebrate development via thyroid hormone signaling pathway in a developmental stage-dependent manner. Environ. Sci. Technol. 48, 8227-8234. https://doi.org/10.1021/es502366g

53. Zhou, H., Yin, N.Y., Faiola, F., 2020. Tetrabromobisphenol A (TBBPA): a controversial $\begin{array}{lllll}\text { environmental pollutant. J. } & \text { Jnviron. }\end{array}$ https://doi.org/10.1016/j.jes.2020.04.039 
54. Zhu, B., Zhao, G., Yang, L., Zhou, B., 2018. Tetrabromobisphenol A caused neurodevelopmental toxicity via disrupting thyroid hormones in zebrafish larvae. Chemosphere 197, 353-361. https://doi.org/10.1016/j.chemosphere.2018.01.080

55. Yu, Y., Hou, Y., Dang, Y., Zhu, X., Li, Z., Chen, H., Xiang, M., Li, Z., Hu, G., 2021. Exposure of adult zebrafish (Danio rerio) to Tetrabromobisphenol A causes neurotoxicity in larval offspring, an adverse transgenerational effect. J. Hazard Mater. 414, 125408. https://doi.org/10.1016/j.jhazmat.2021.125408

\section{Figure Legends}

\section{Figure 1 - Effect of TBBPA (1, 10 and $100 \mu \mathrm{g} / \mathrm{L})$ on larval phenotypes at 48 hpf.}

A) percentage of different phenotypes: normally developed D-Veligers (white), malformed larvae, (light gray), immature larvae with protruding mantle (dark grey), arrested trochophorae (black). Measurements were made on at least 50 larvae for each experimental condition obtained from 5 parental pairs $(\mathrm{N}=5)$.

B) representative images of the main phenotypes obtained with calcofluor/calcein staining in larvae exposed to $10 \mu \mathrm{g} / \mathrm{L}$ TBBPA, showing organic matrix (blue) and calcified areas (green) in the growing shell (scale bar: $20 \mu \mathrm{m})$.

Figure 2 - Effects of TBBPA $(10 \mu \mathrm{g} / \mathrm{L})$ on shell morphology of Mytilus larvae at $48 \mathrm{hpf}$, evaluated by SEM.

A) control samples with symmetric valvae, straight hinge, uniform surfaces. B-E) TBBPA-exposed samples, showing shells with irregular surfaces, holes (arrowhead in B), fractures (C-E), convex hinges $(C, D)$. Fractures perpendicular to the hinge were often observed (D, square in E enlarged in F). 

by SEM.

A) control D-veligers, with symmetric valvae and uniform surface. B-D) TBBPA-exposed samples, showing malformed shell with fractures perpendicular to the hinge region (B), immature shells, characterized by polygonal shapes and asymmetric valvae (C, D). E-F) details of D (squares), showing protruding mantle $(\mathrm{E})$, and irregular calcification at the center of the valvae $(\mathrm{F})$.

Figure 4 - Effect of TBBPA (10 and $100 \mu \mathrm{g} / \mathrm{L})$ on the time course of early shell formation in $M$. galloprovincialis from the trochophora to the first D-veliger stage at different times postfertilization (from top to bottom: at $24,28,32,48 \mathrm{hpf}$ ).

Columns correspond to experimental conditions (from left to right: Control, 10 and $100 \mu \mathrm{g} / \mathrm{L}$ TBBPA). Representative images (lateral view) show merged fluorescent signals of calcofluor (blue) and calcein (green) staining, respectively, the organic matrix and $\mathrm{CaCO}_{3}$ deposition. White arrowheads indicate missing calcification in the centre of each valva (scale bars: $10 \mu \mathrm{m}$ ).

Figure 5 - Effect of TBBPA (10 and $100 \mu \mathrm{g} / \mathrm{L})$ on the growth of organic matrix (blue) and calcified shell (green) in mussel larvae.

Areas of each shell component $\left(\mu \mathrm{m}^{2}\right)$ measured in a single valva of TBBPA-exposed larvae are reported as \% values of control (unexposed) larvae at 24 (A), 28 (B) and $32 \mathrm{hpf}(\mathrm{C})$. In D) ratios of areas matrix/calcified shell in different experimental conditions are reported. Measurements were made on at least 50 larvae for each condition obtained from 4 parental pairs $(\mathrm{N}=4)$. ${ }^{*} \mathrm{p} \leq 0.05$, TBBPAexposed vs Controls; \# Control 28 hpf vs 32 hpf. Oneway ANOVA Kruskall-Wallis followed by 739 Tukey's test. 
Controls (white bars); TBBPA (10 $\mu \mathrm{g} / \mathrm{L})$ (grey bars).

744 A) Chitin synthase; B) tyrosinase; C) carbonic anhydrase; D) Extrapallial Protein.

745 Data, reported as fold changes with respect to eggs, represent the mean $\pm \mathrm{SD}(\mathrm{N}=4)$. Data were 746 analysed by one way ANOVA Kruskall-Wallis followed by Tukey's test and statistical differences 747 between control and TBBPA-exposed samples at each developmental stage are reported $(*=\mathrm{p}<0.01)$. 748 As previously described (Miglioli et al., 2019), expression of all transcripts was significantly different 749 at all times pf with respect to eggs $(\mathrm{p}<0.01$, not shown $)$.

750

Figure 7 - Expression pattern of Tyrosinase and Chitinase in control and TBBPA-exposed larvae of M. galloprovincialis evaluated by ISH at different times pf.

Figure 8 - Expression pattern of dopaminergic components control and TBBPA-exposed larvae of M. galloprovincialis evaluated by ISH at different times pf.

C: Control; TBBPA (10 $\mu \mathrm{g} / \mathrm{L})$; rows (from top to bottom: 24, 28, 32, $48 \mathrm{hpf}$ ). Tyrosine Hydroxylase (TH), Dopamine- $\beta$-Hydroxylase (DßH), Dopamine Receptor 1 (DR1). Scale bar: $20 \mu \mathrm{m}$.

Figure 9 - Confocal images of serotonin immunoreactive cells (5-HT-ir) in early larval stages of

5-HT-ir cells are shown in Red/Pink (Ex/Em: 590/617 nm), Hoechst stained nuclei are shown in blue

Rows: 24, 28, 32 hours post fertilization-hpf.

765 Columns:

766 a) brightfield images; scale bar: $20 \mu \mathrm{m}$.

b) 5-HT and Hoechst merged channels; scale bar: $20 \mu \mathrm{m}$. 
c) 4-5 X magnified images of column; white asterisks indicate the nuclei of 5-HT-ir cells (*) and white arrowheads emerging neurites, respectively; scale bar: $5 \mu \mathrm{m}$.

770

Figure 10 - Confocal images of serotonin immunoreactive cells (5-HT-ir) in early larval stages of M. galloprovincialis at $48 \mathrm{hpf}$.

5-HT-ir cells are shown in Red/Pink (Ex/Em: 590/617 nm), Hoechst stained nuclei are shown in blue

(Ex/Em: 358/461 nm). A) control; B) TBBPA (10 $\mu \mathrm{g} / \mathrm{L})$. In B) 5-HTR immunoreactivity is reported in representative TBBPA-induced phenotypes.

Columns:

a) brightfield images; scale bar: $20 \mu \mathrm{m}$.

b) 5-HT and Hoechst merged channels; scale bar: $20 \mu \mathrm{m}$.

c) 4-5 X magnified images of column; white asterisks indicate the nuclei of 5-HT-ir cells, showing that TBBPA-induced phenotypic alterations are associated with a reduction in the number of 5-HTir cells (*); arrowheads indicate emerging neurites; scale bar: $5 \mu \mathrm{m}$.

Figure 11 - Effect of TBBPA $(10 \mu \mathrm{g} / \mathrm{L})$ on development of serotonin immunoreactive cells (5HT-ir) in mussel larvae at $48 \mathrm{hpf}$.

Box plot reporting the number of 5-HT-ir cells quantified in at least 12 larvae from 4 different parental pairs $(\mathrm{N}=4)$. Data are reported as mean $\pm \mathrm{SD}$, indicating significant differences between control and TBBPA-exposed samples $*=p<0.01$ (Mann-Whitney U test).

Figure 12 - Confocal images of GABA immunoreactive cells (GABA-ir) in early larval stages of

\section{M. galloprovincialis from 24 to 32 hpf.}

GABA-ir cells are shown in Red/Pink (Ex/Em: 590/617 nm), Hoechst stained nuclei are shown in

blue (Ex/Em: 358/461 nm). A) control; B) TBBPA (10 $\mu \mathrm{g} / \mathrm{L})$.

Rows: 24, 28, 32 hours post fertilization-hpf. 
794 Columns:

795 a) brightfield images; scale bar: $20 \mu \mathrm{m}$.

796 b) GABA and Hoechst merged channels; the z-stack acquisition is indicated in white (see Fig. S3). 797 Red arrowheads indicate the shell field region, and the perimeter of the larvae is indicated by a white 798 dotted line; scale bar: $20 \mu \mathrm{m}$.

799

800 Figure 13 - Confocal images of GABA immunoreactive cells (GABA-ir) in early larval stages of 801 M. galloprovincialis at 48 hpf.

802 GABA-ir cells are shown in Red/Pink (Ex/Em: 590/617 nm), Hoechst stained nuclei are shown in 803 blue (Ex/Em: 358/461 nm). A) control; B) TBBPA $(10 \mu \mathrm{g} / \mathrm{L})$. In B) GABA immunoreactivity is 804 reported in representative TBBPA-induced phenotypes.

805 a) brightfield images; scale bar: $20 \mu \mathrm{m}$.

806 b) GABA and Hoechst merged channels, shown in 3 different z-stack acquisitions indicated in white 807 (see Fig. S4). Red arrowheads indicate the hinge region, and the perimeter of the larvae is indicated 808 by a white dotted line; scale bar: $20 \mu \mathrm{m}$. 


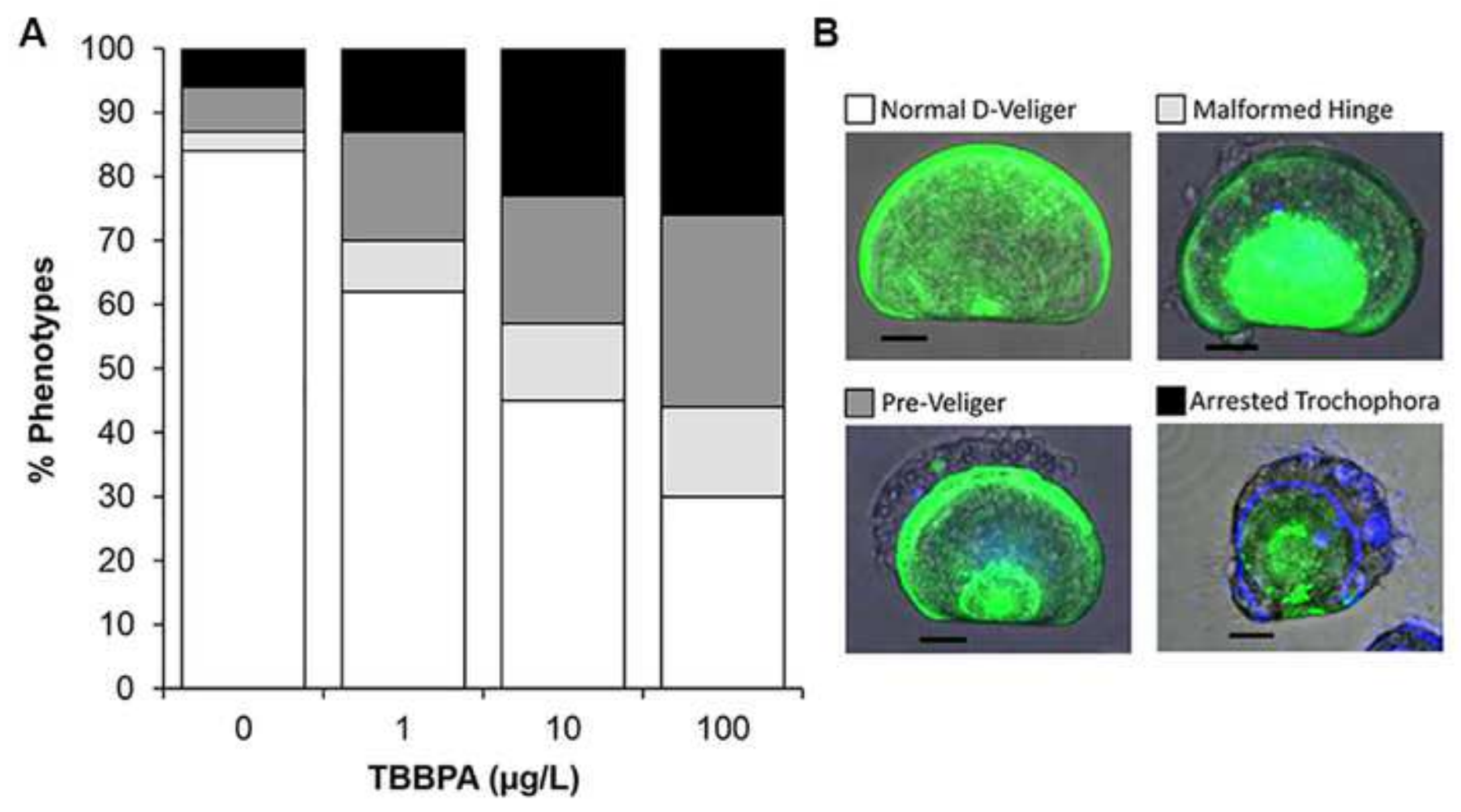



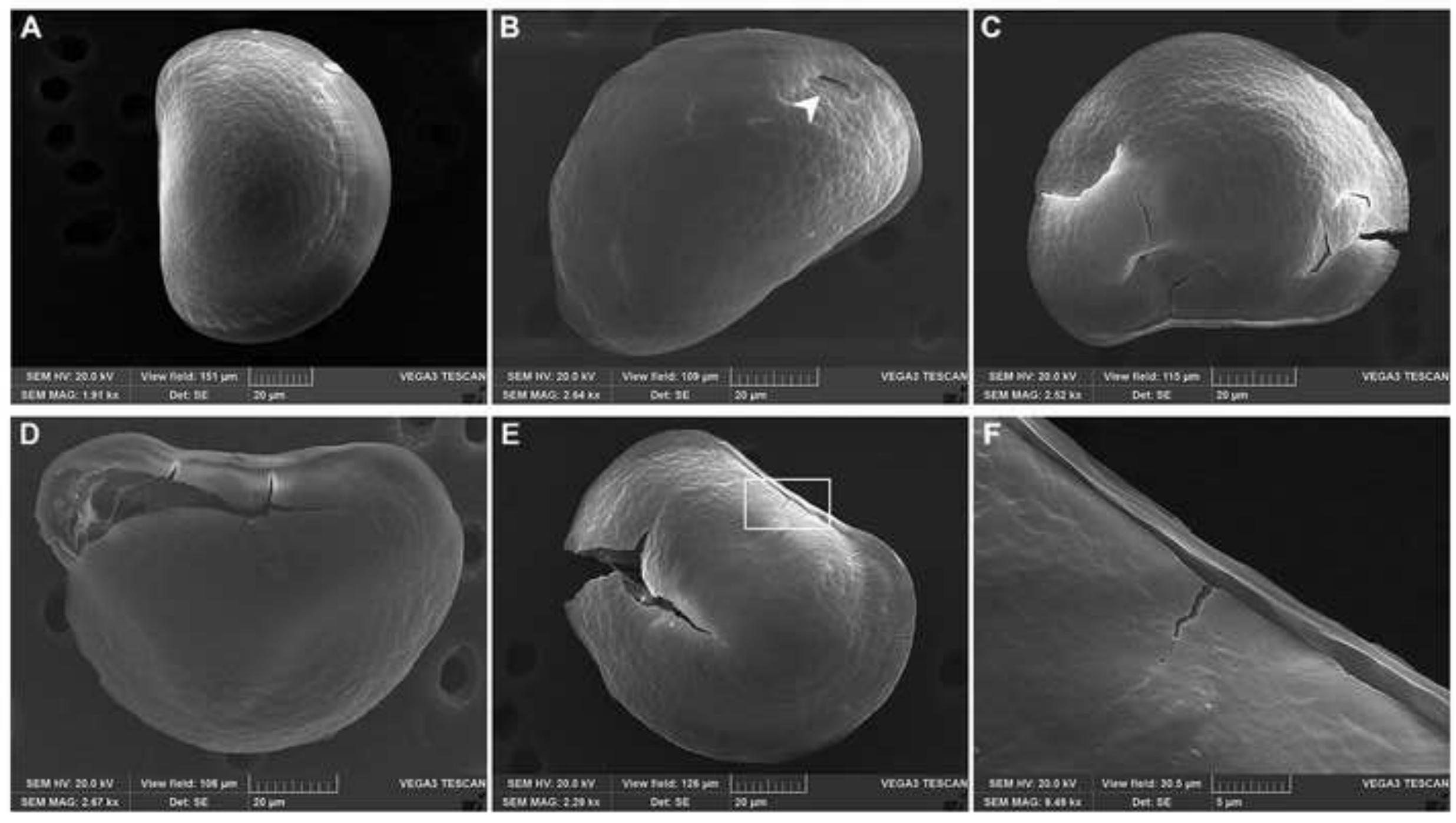

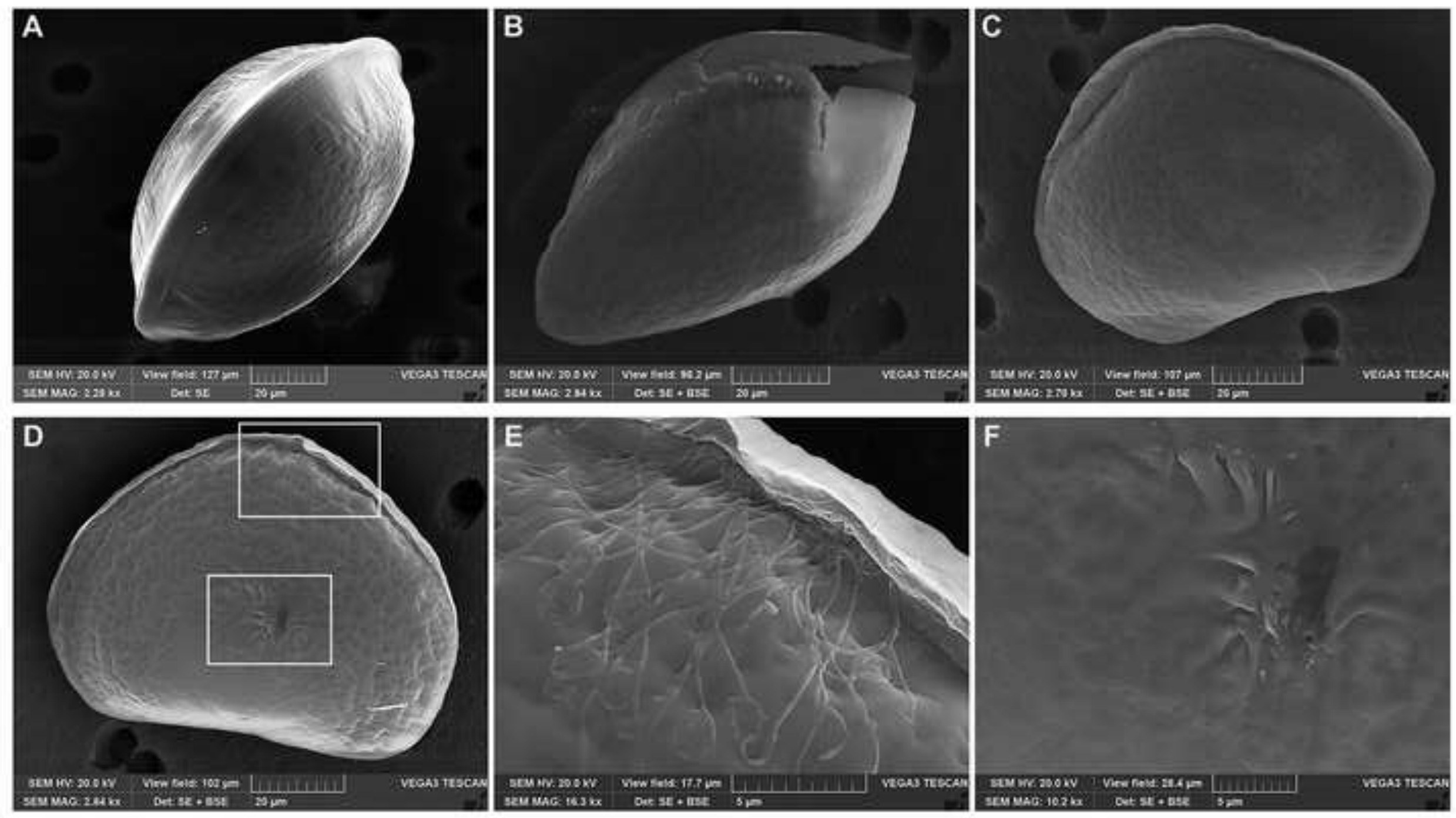


\section{TBBPA $(\mu \mathrm{g} / \mathrm{L})$}

0

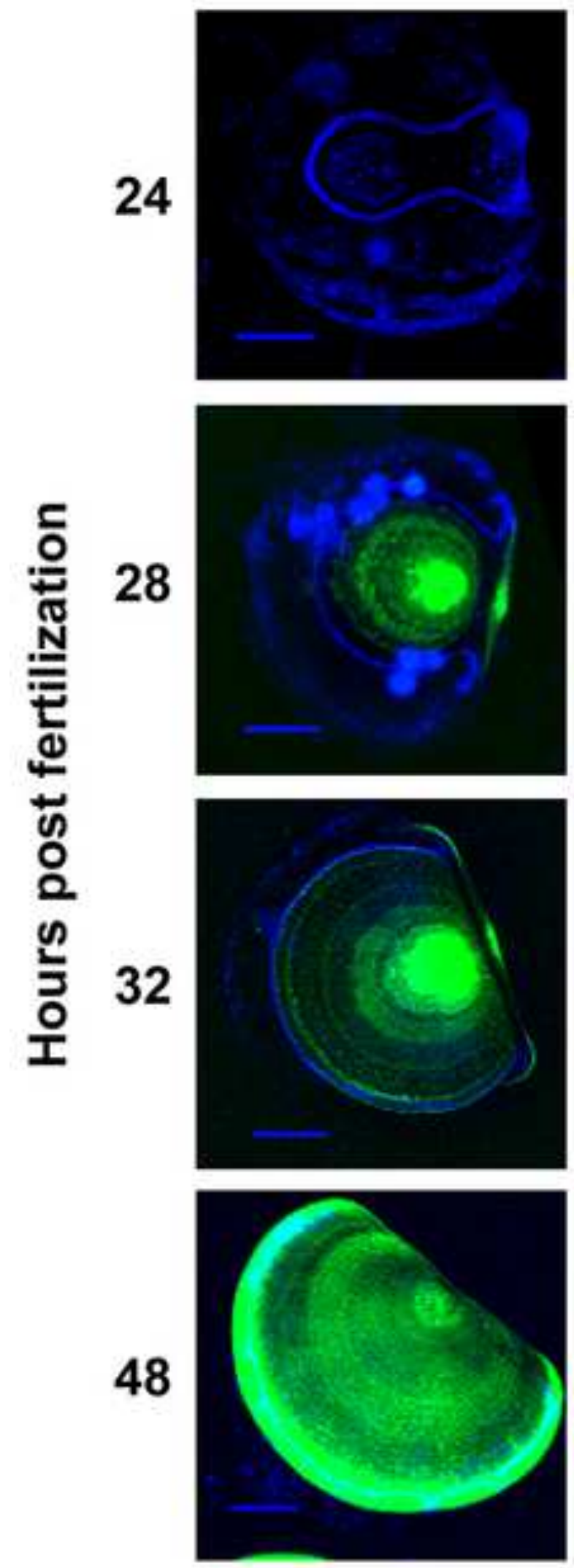

10
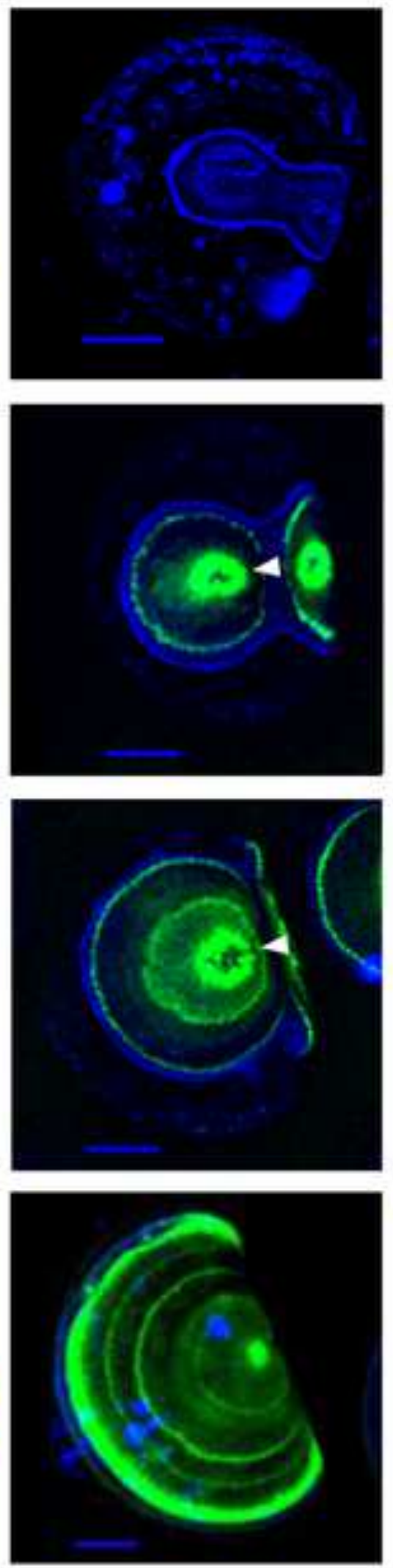

100
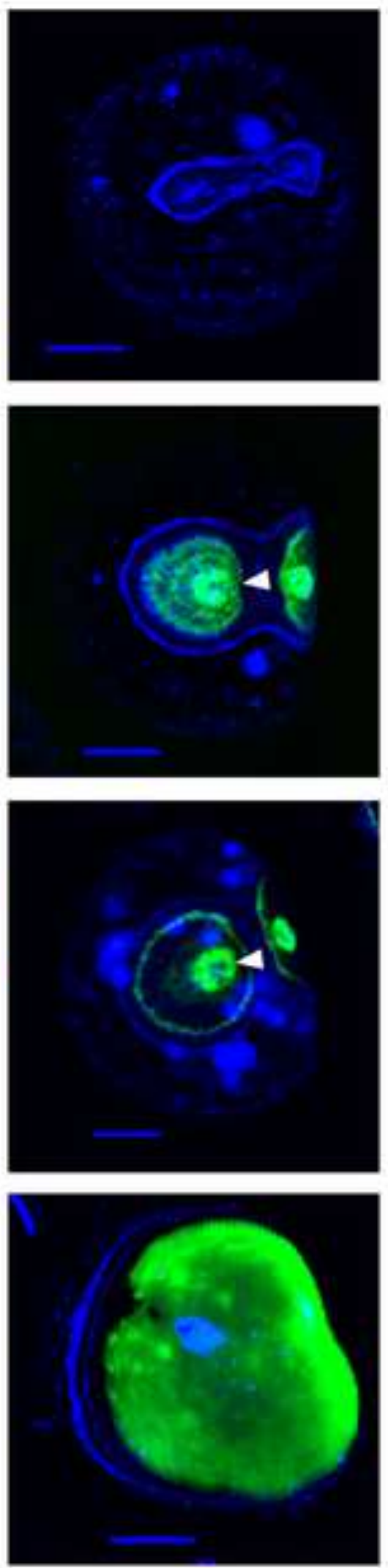


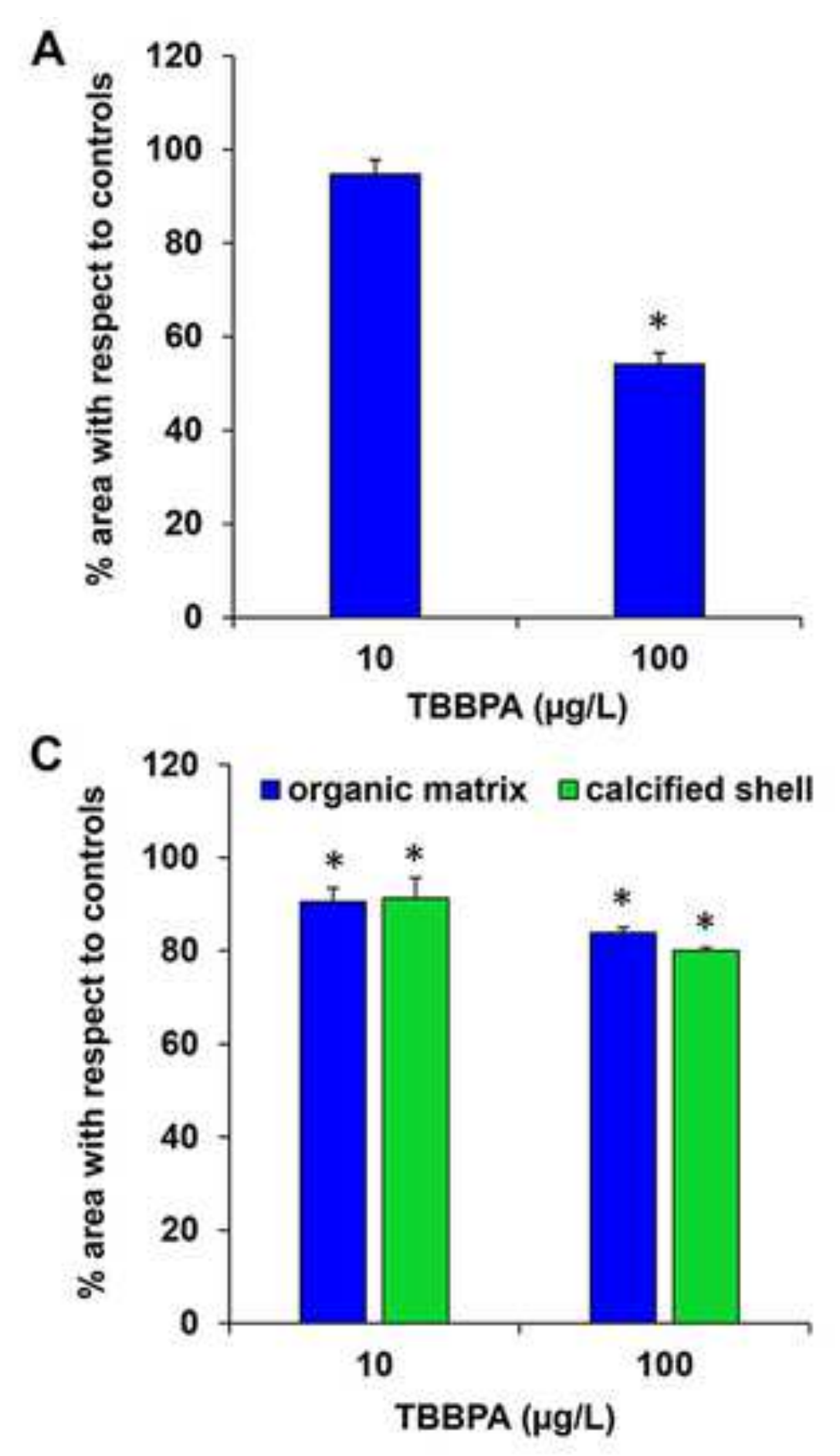

B
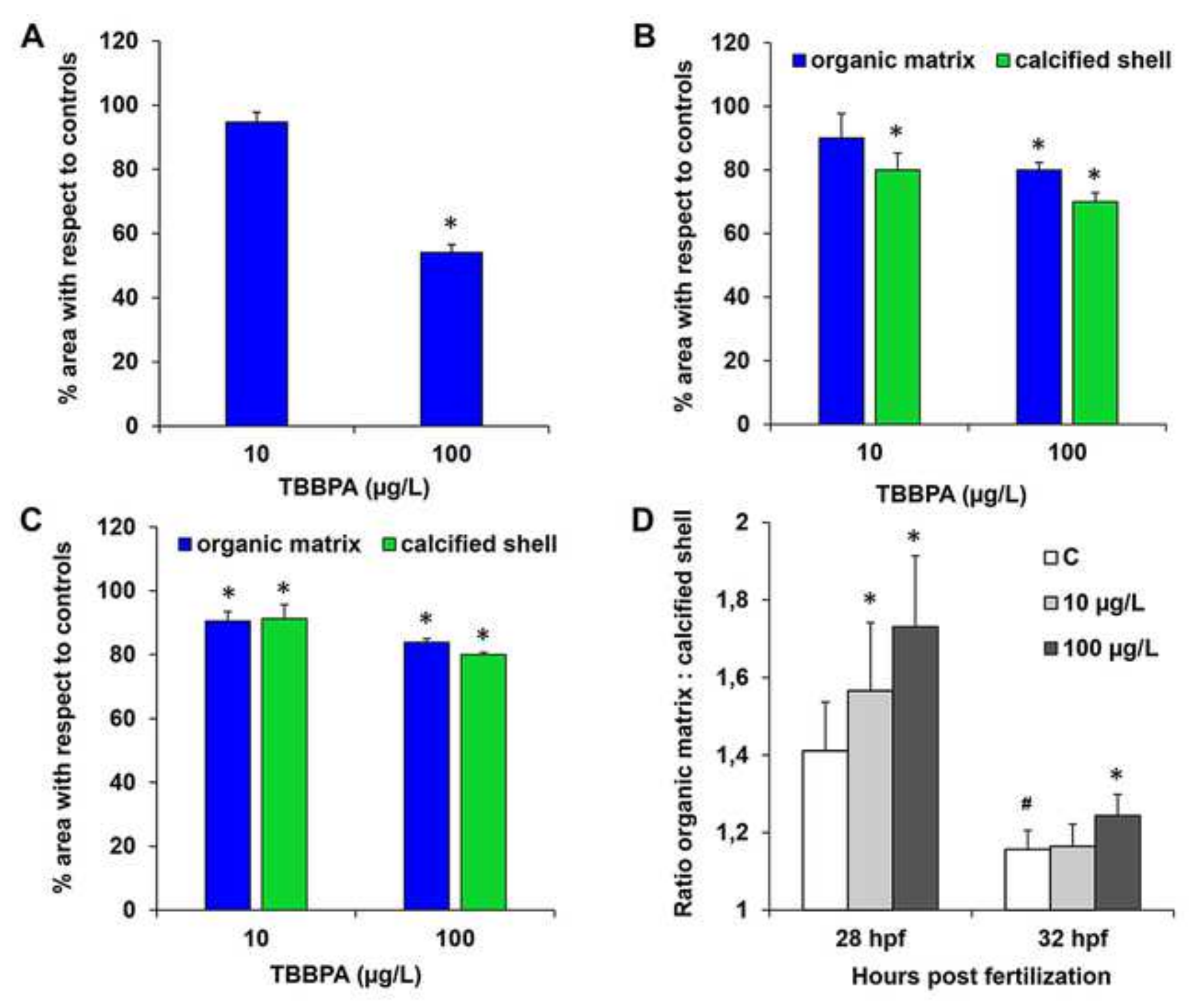

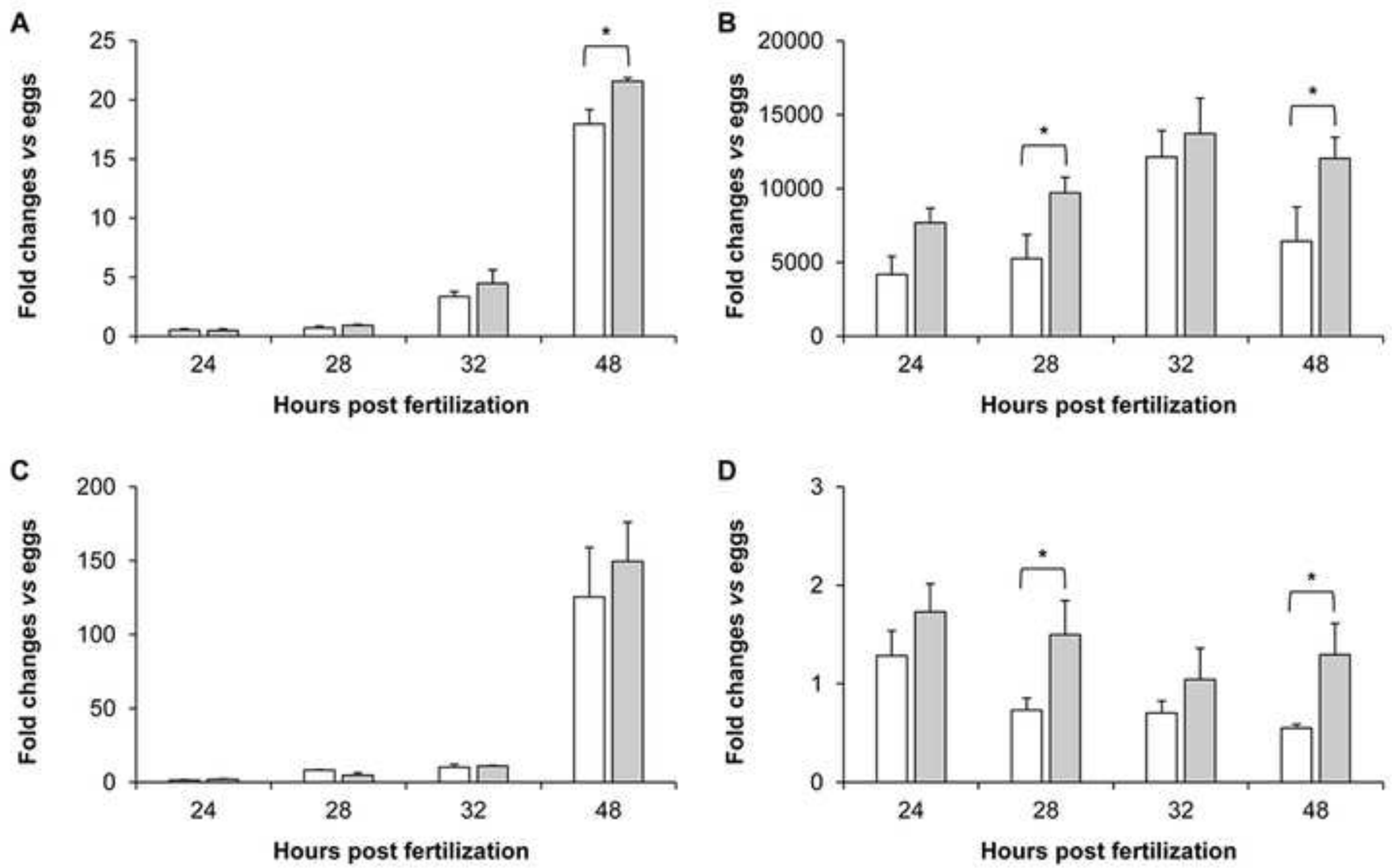


\section{Tyrosinase}

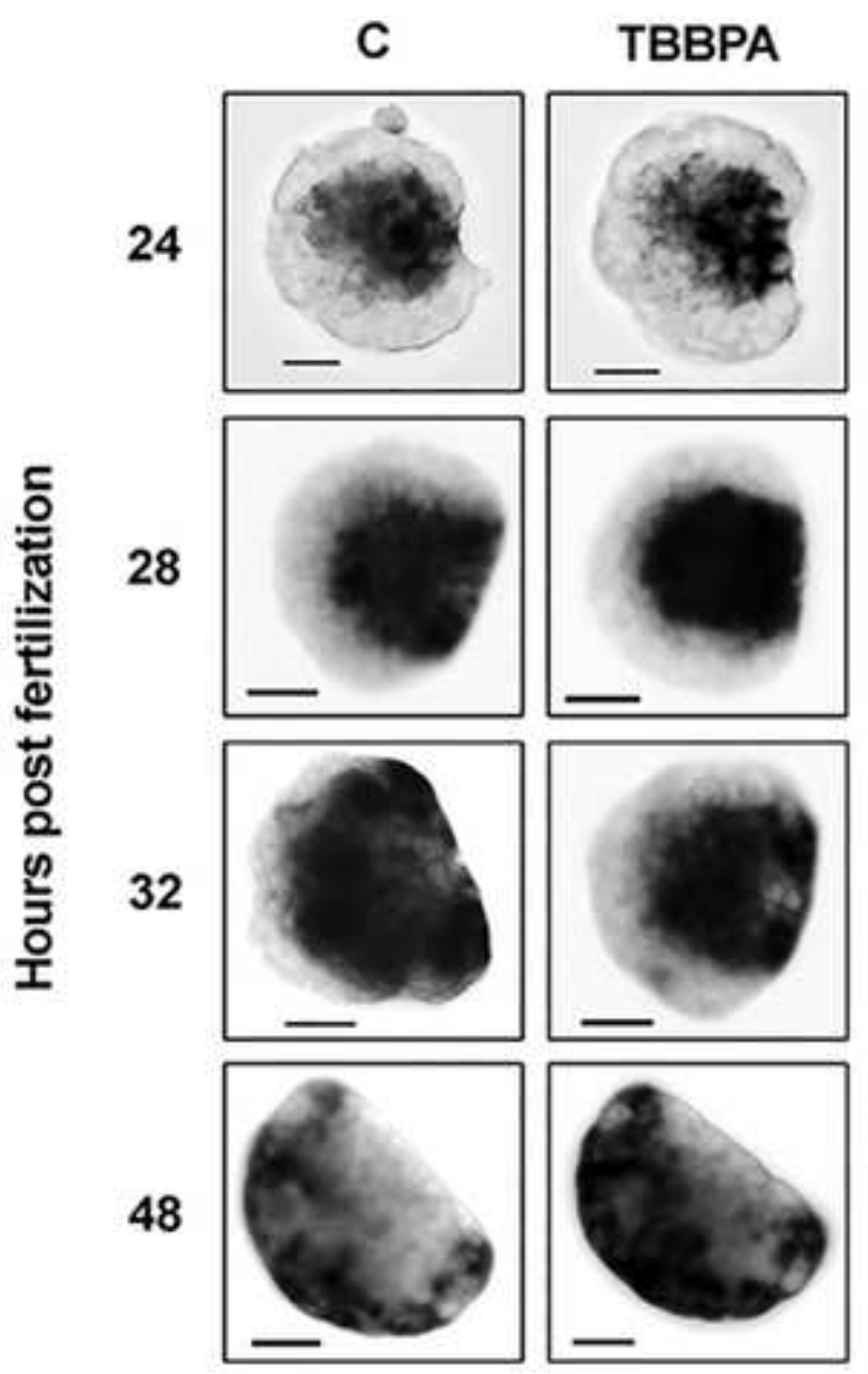

\section{Chitinase}
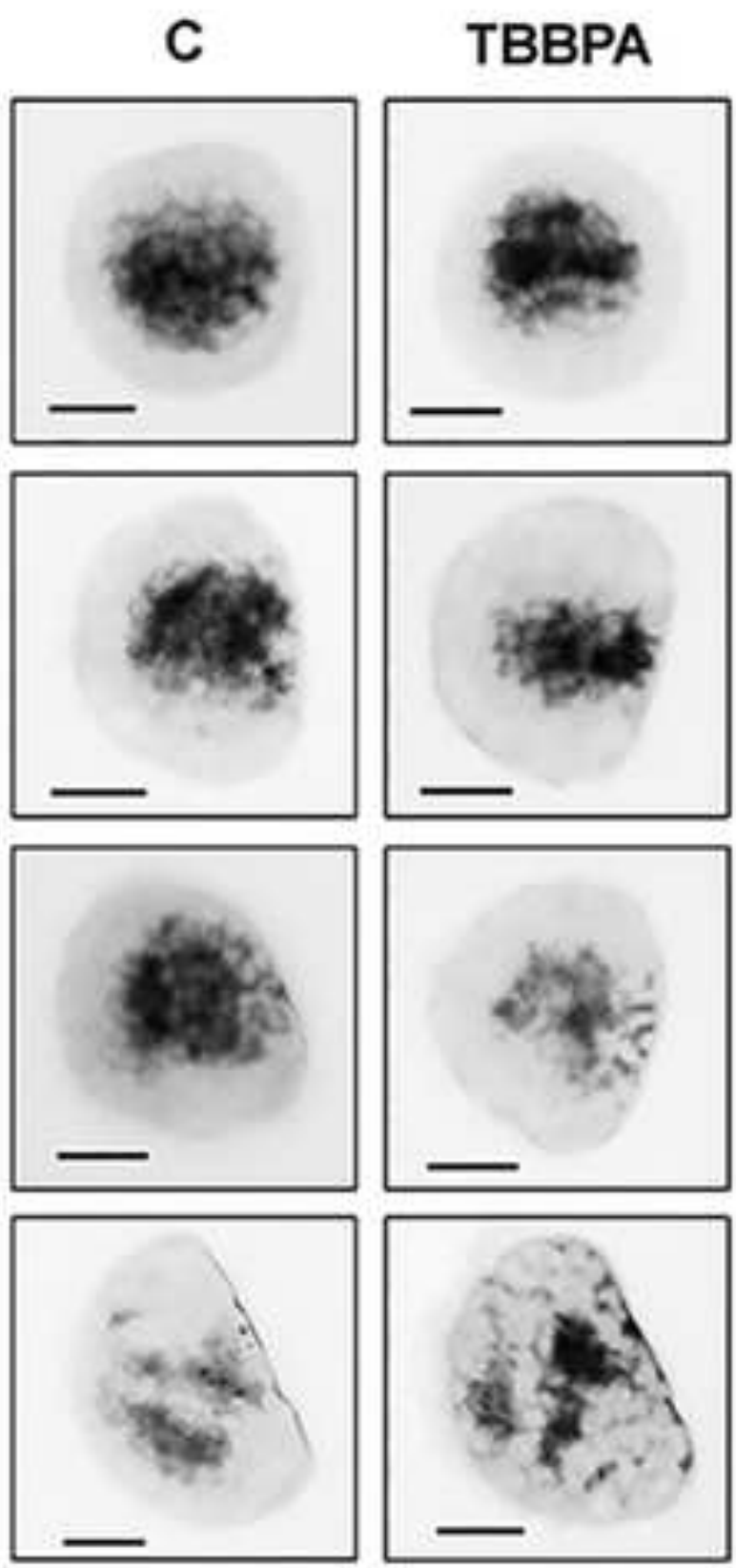


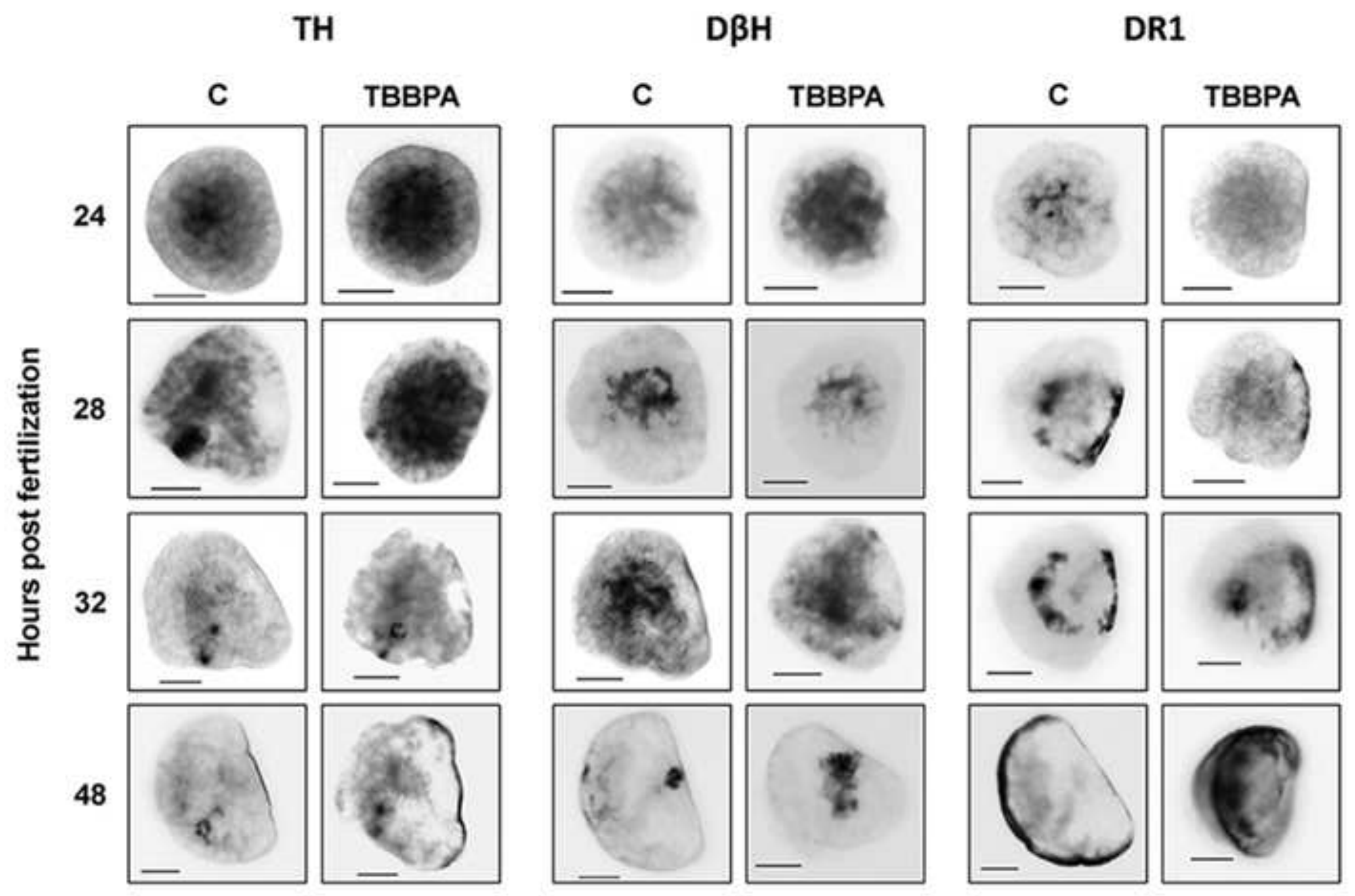



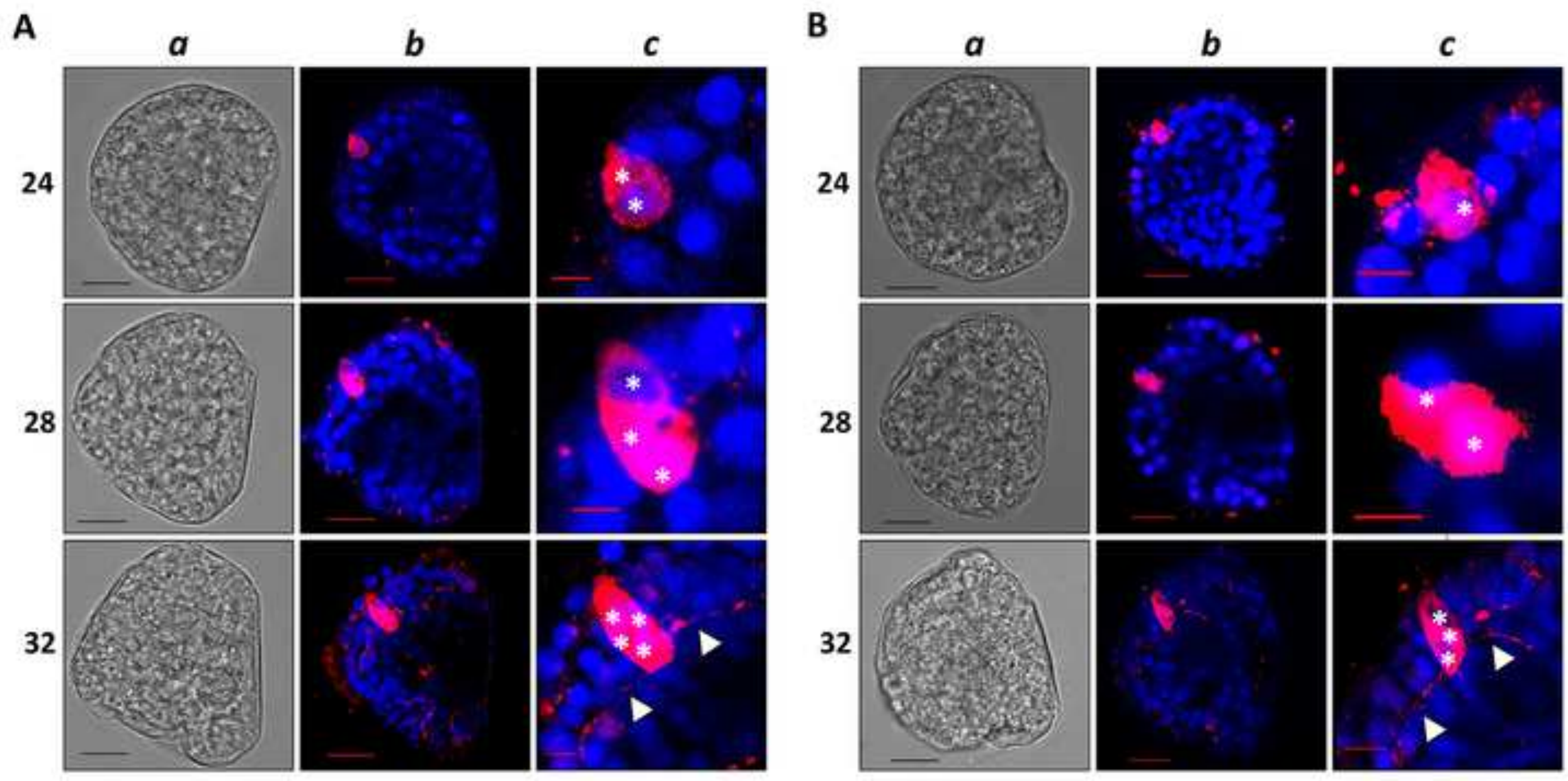
A
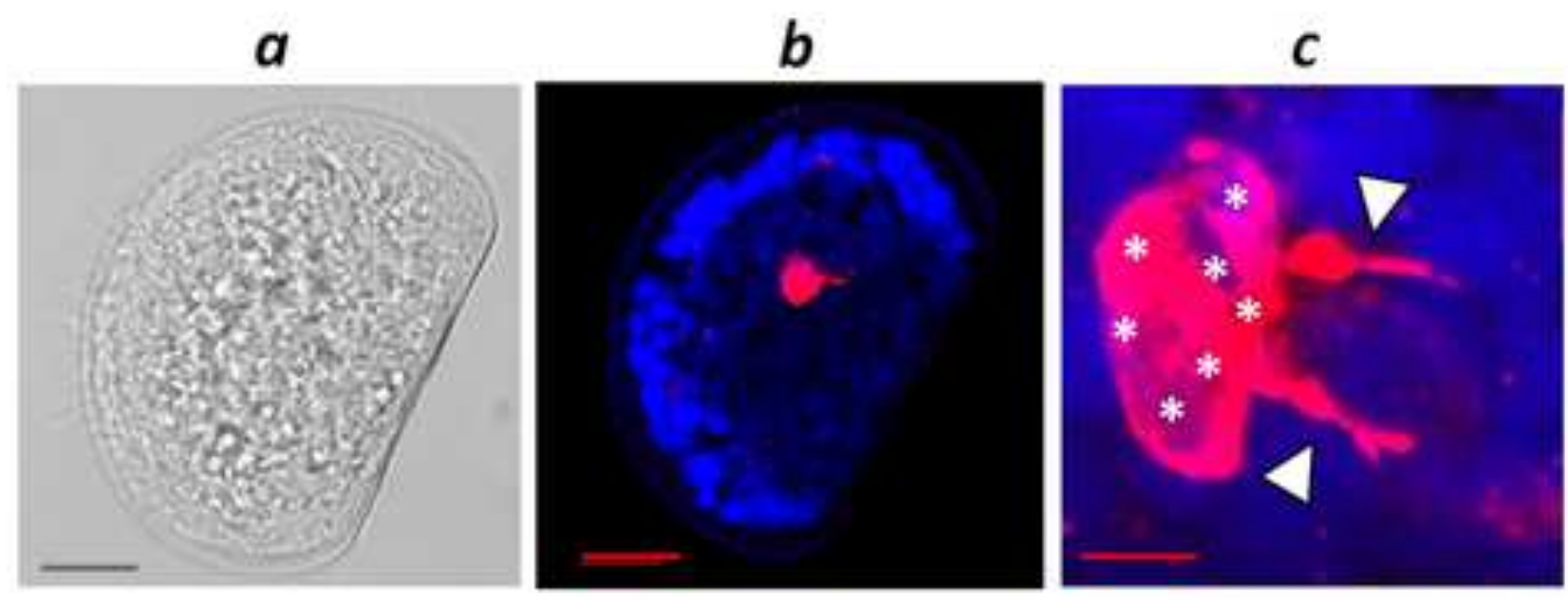

B
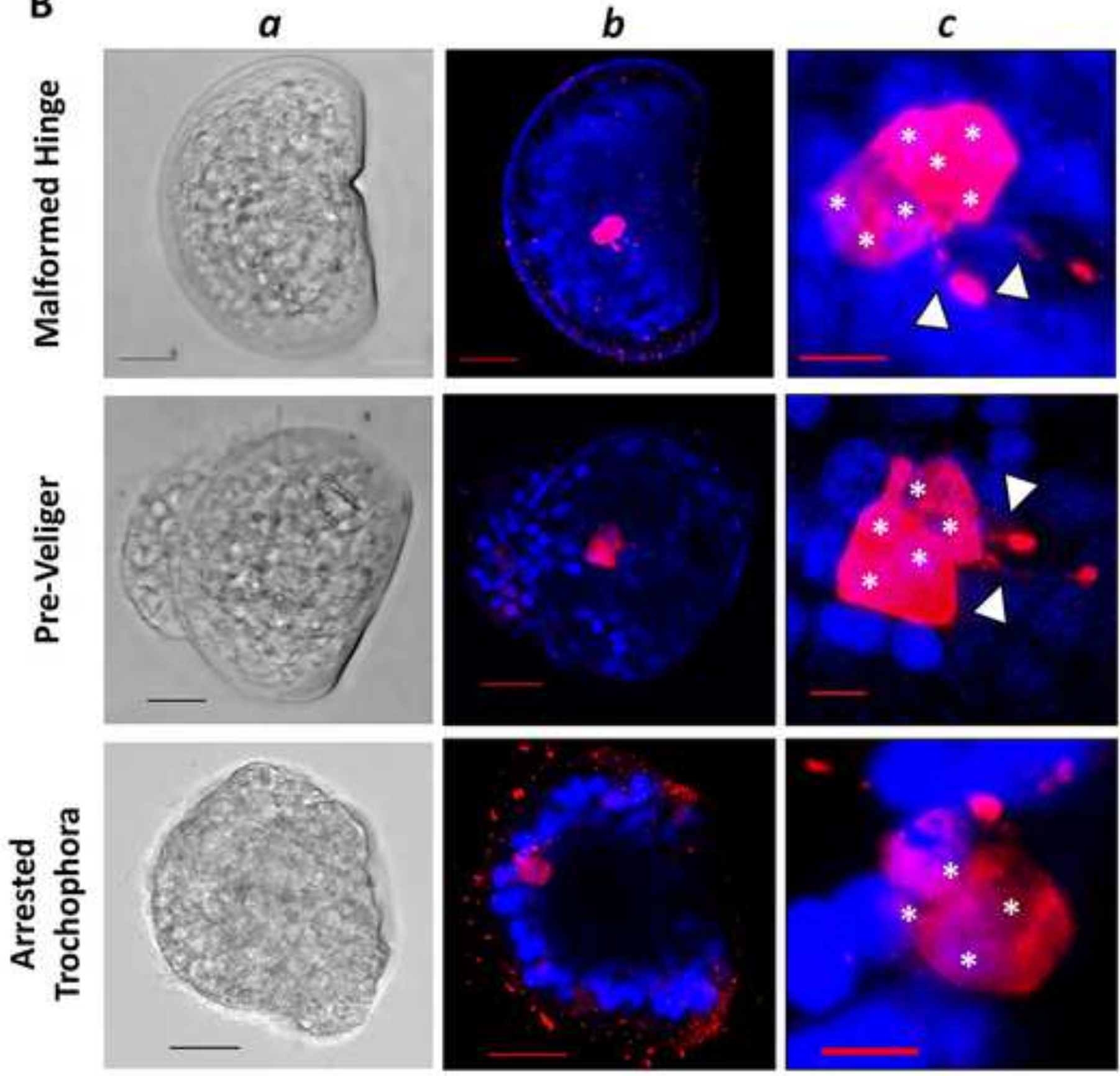

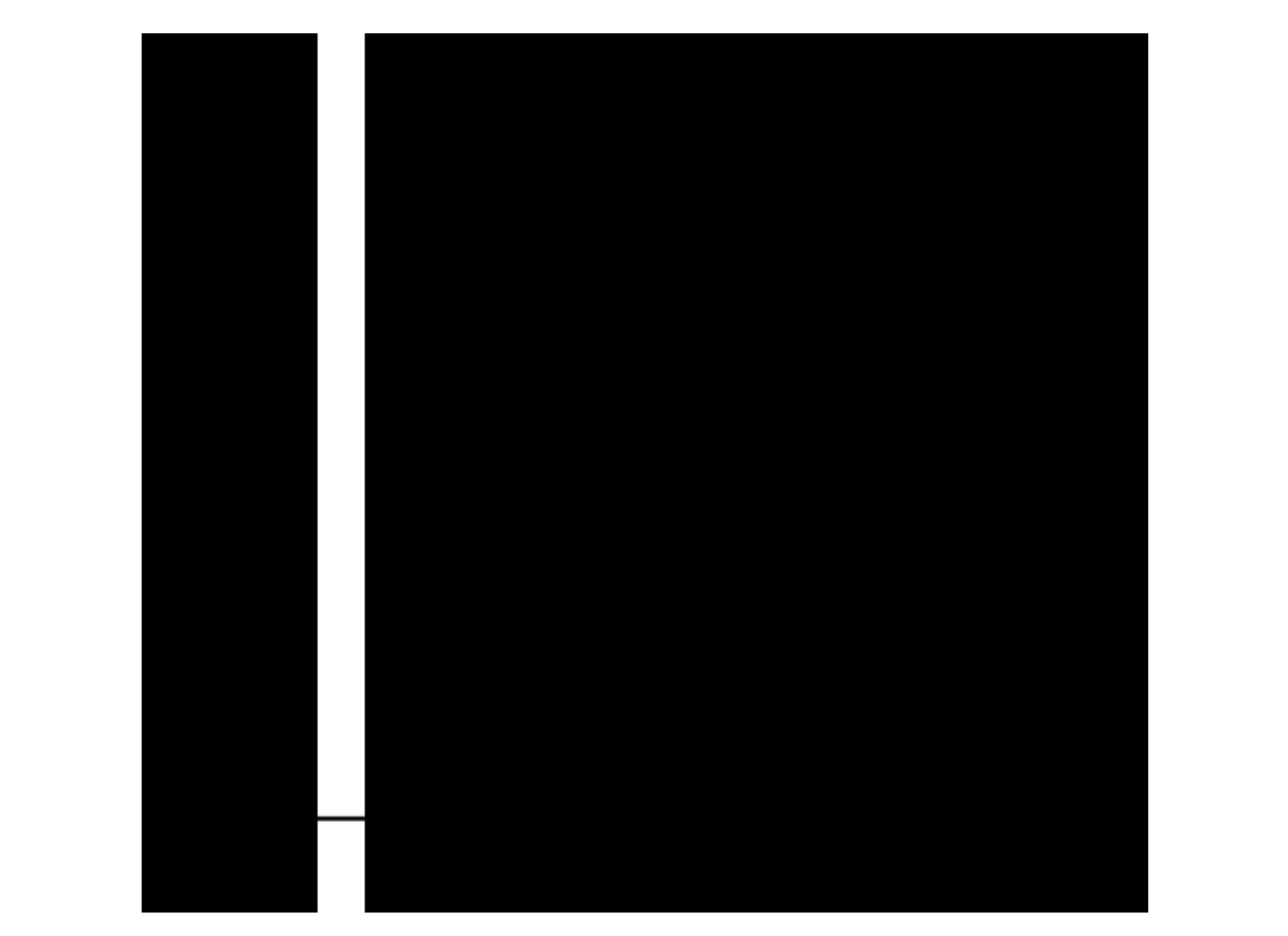
A
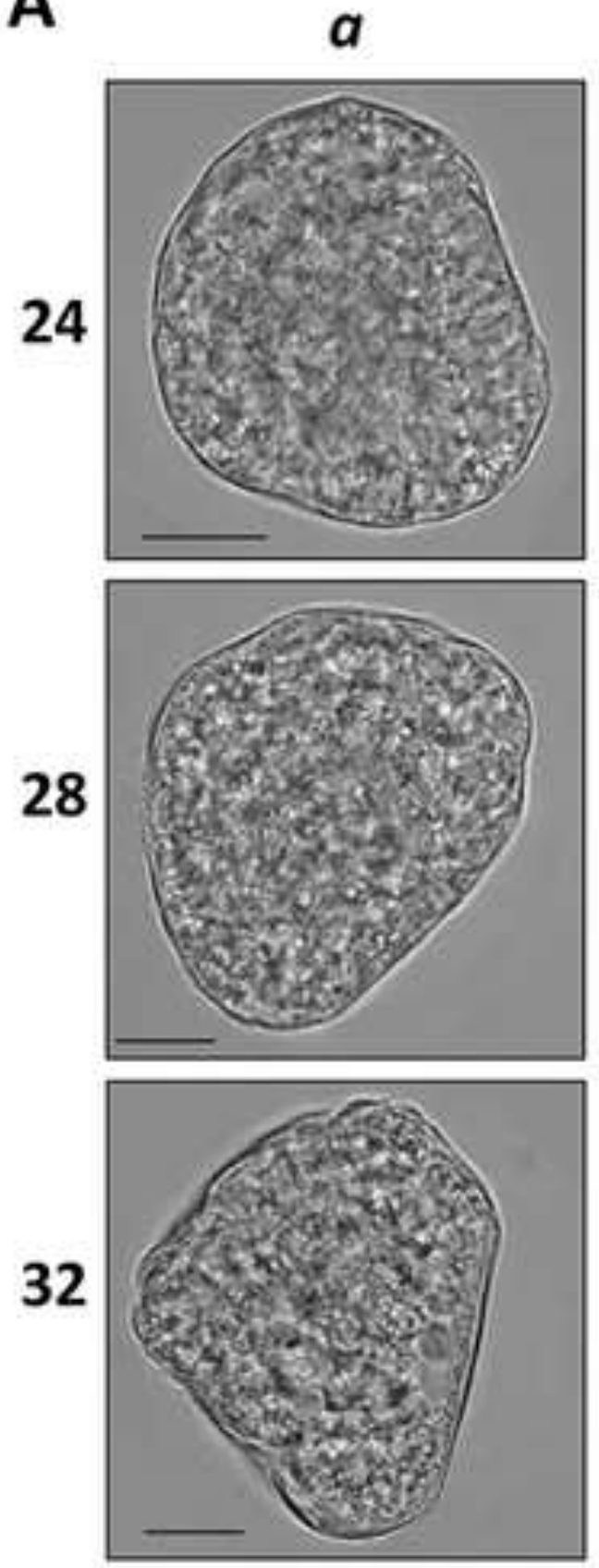

b
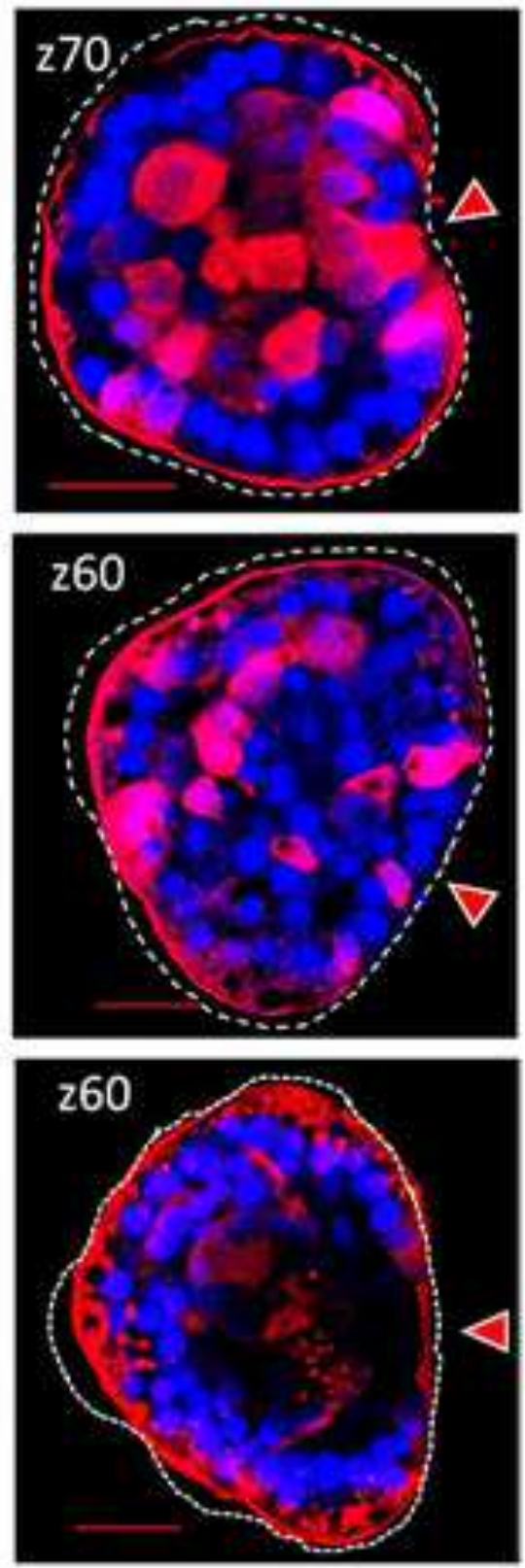

B

$a$
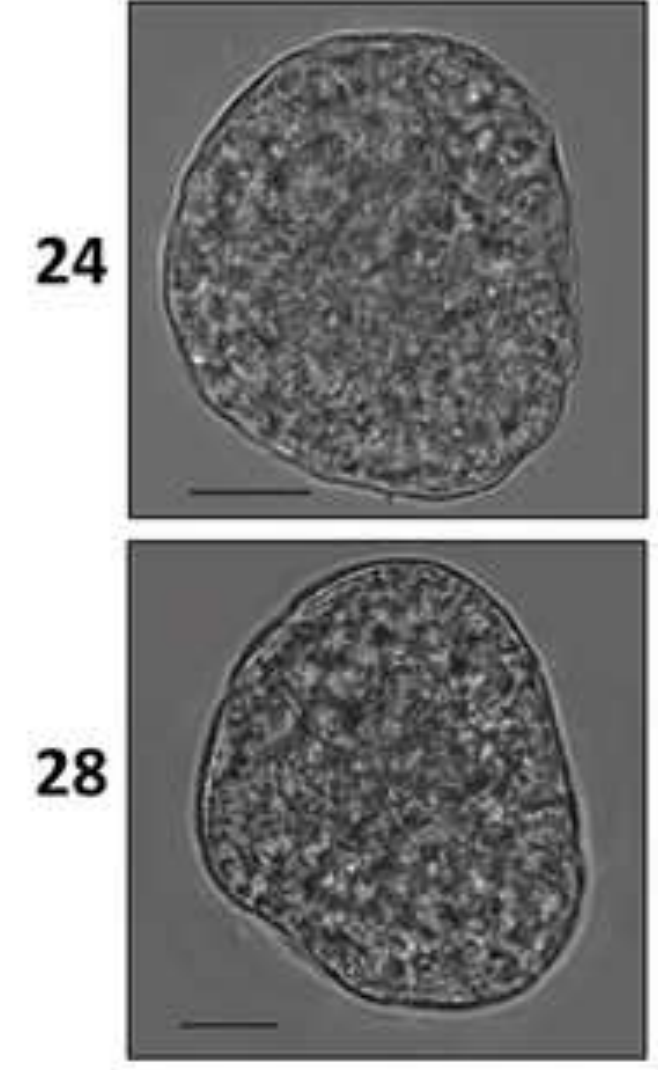

28

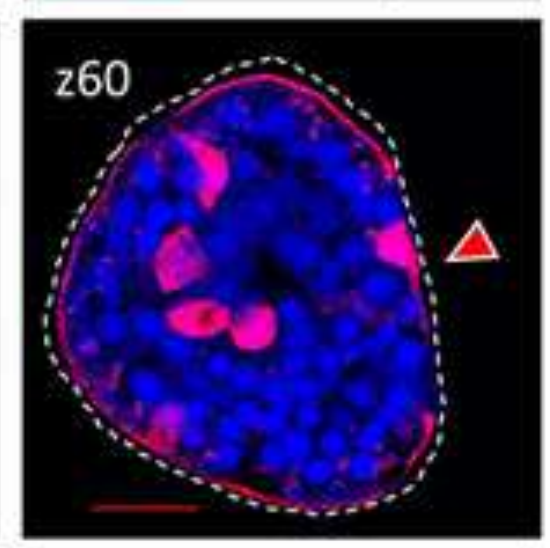

32

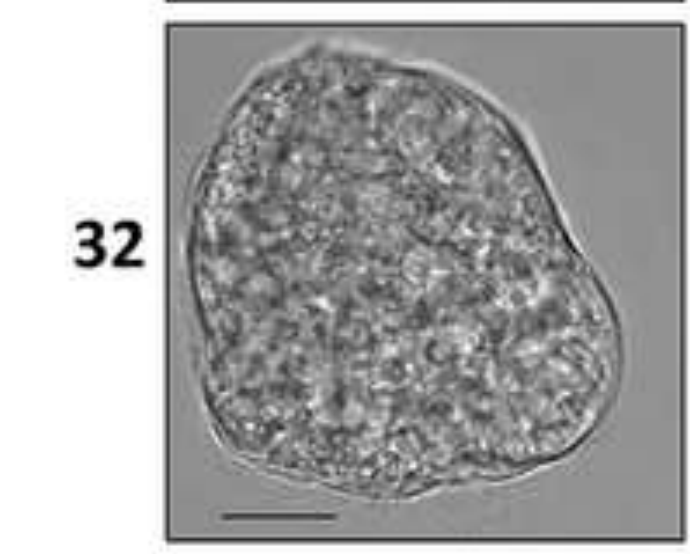

b

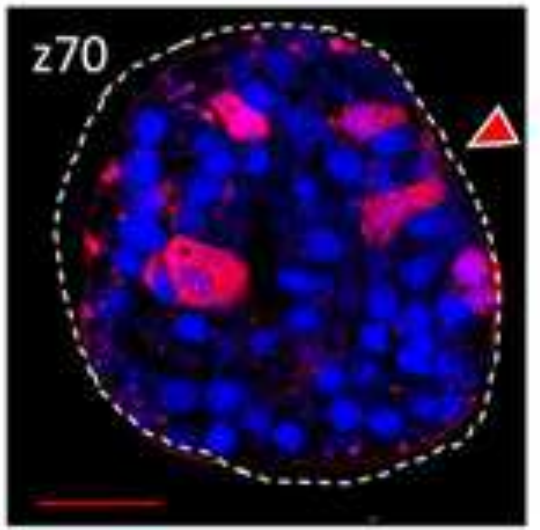

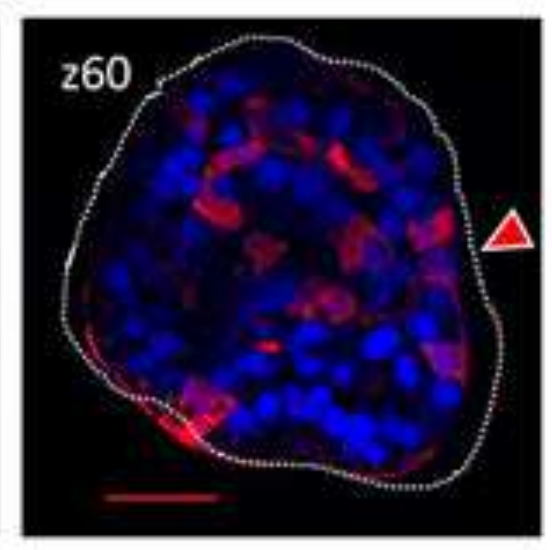


A
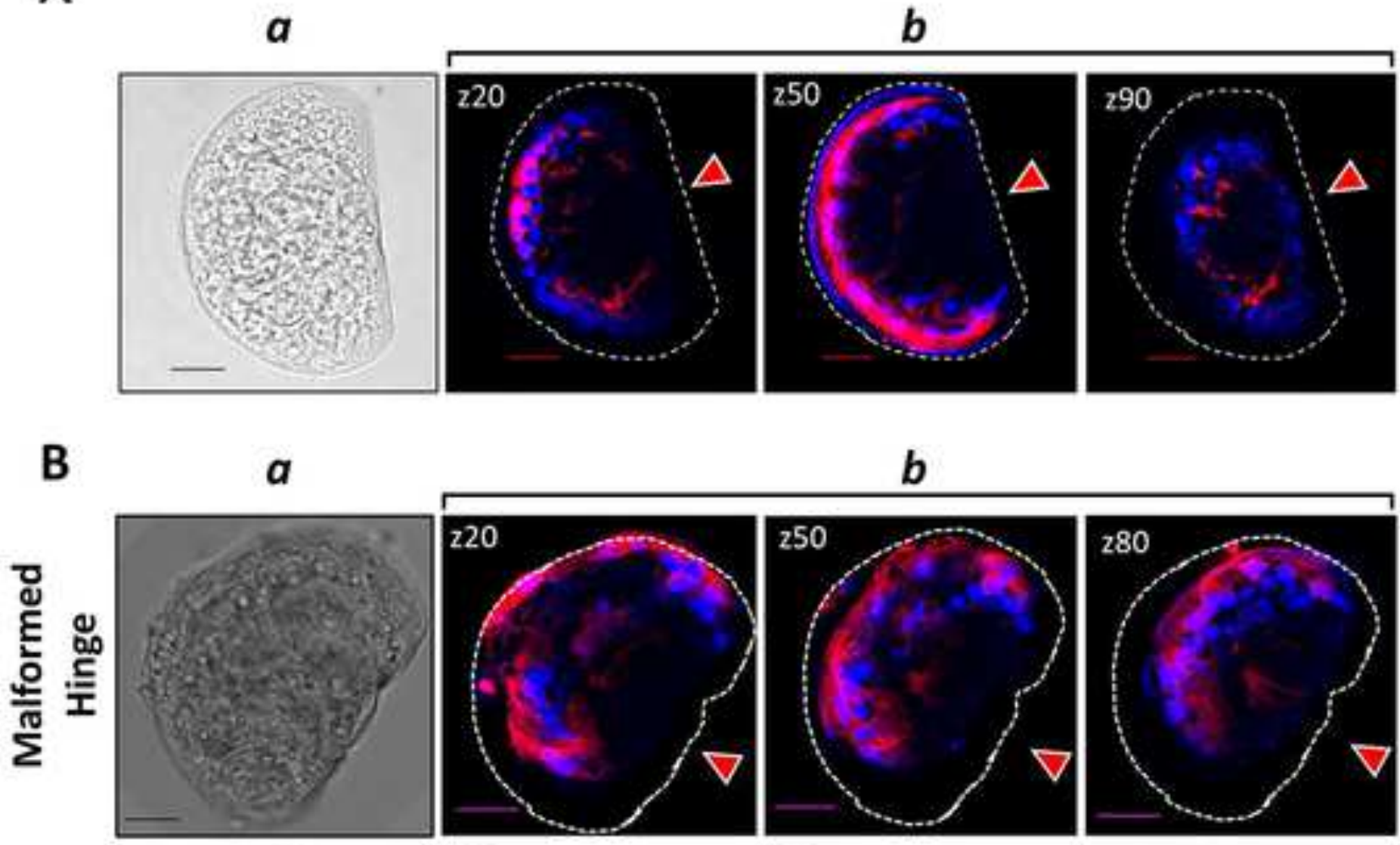

b
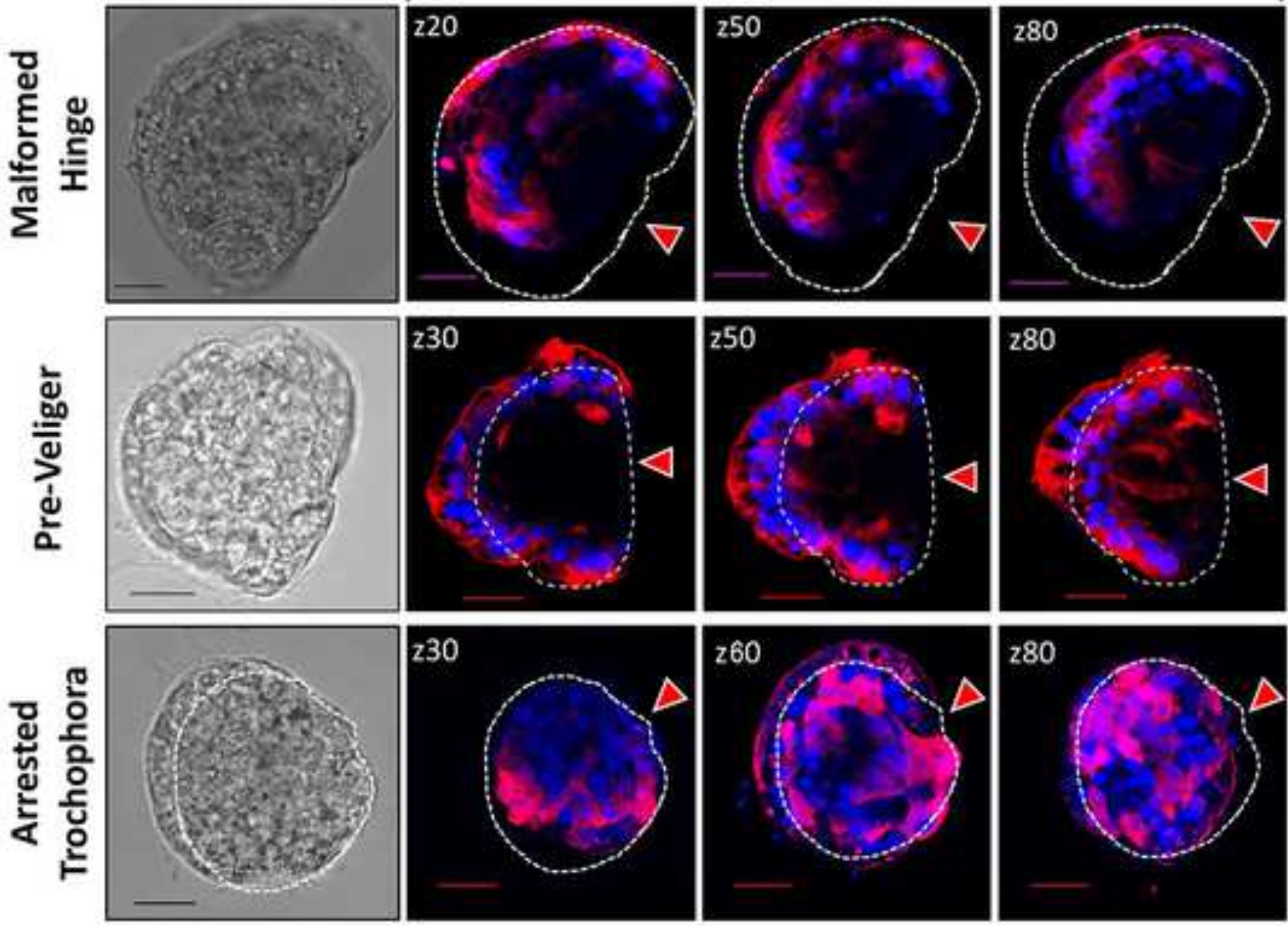
Click here to access/download Supplementary material for on-line publication only Miglioli et al., Supplementary info revised.docx 


\section{CRediT authorship contribution statement}

Angelica Miglioli: Investigation, Methodology, Data curation, Writing. Teresa Balbi: Investigation, Data curation, methodology, Writing, review \& editing, funding acquisition. Michele Montagna: data curation, methodology. Remi Dumollard: Conceptualization, Supervision, Writing, funding acquisition. Laura Canesi: Conceptualization, Supervision, Writing. 
SUPPLEMENTARY INFORMATION to Miglioli et al.,

Tetrabromobisphenol A acts as a neuro-developmental disruptor in early larval stages of Mytilus galloprovincialis

$q P C R$

Primers pairs employed for qPCR analysis and their accession numbers in GenBank are reported in

Table S1 (Balbi et al., 2016, 2017, 2018; Miglioli et al., 2019).

\section{Table S1}

\begin{tabular}{|c|c|c|c|c|}
\hline Gene & Primers & $\begin{array}{c}\text { Amplicon } \\
\text { size bp }\end{array}$ & $\begin{array}{c}\text { Amplification } \\
\text { efficiency (\%) }\end{array}$ & $\begin{array}{c}\text { Accession } \\
\text { number }\end{array}$ \\
\hline$E F 1$ & $\begin{array}{c}\text { 5'-CGTTTTGCTGTCCGAGACATG -3 } \\
\text { 5'-CCACGCCTCACATCATTTCTTG -3' }\end{array}$ & 135 & 99 & AB162021 \\
\hline Hel & $\begin{array}{c}\text { 5'-GCACTCATCAGAAGAAGGTGGC -3' } \\
\text { 5'-GCTCTCACTTGTGAAGGGTGAC -3' }\end{array}$ & 129 & 132 & DQ158075 \\
\hline$C S$ & $\begin{array}{c}\text { 5'-AACAGAAGCCAGGCACTATATC -3' } \\
\text { 5'- GTCAGAACCAGCACAGTAGTC -3' }\end{array}$ & 106 & 104 & EF535882 \\
\hline$C A$ & $\begin{array}{c}\text { 5'-ACCAGATGGTCTTGCAGTTT -3' } \\
\text { 5'- TCATCTCTGACTGCTGCTAATG -3' }\end{array}$ & 102 & 95 & LK934681 \\
\hline$E P$ & $\begin{array}{c}\text { 5'- TAAACTCTGGACACGCATACC -3' } \\
\text { 5'-GAGTCCCTCTTGGTGCATATT -3' }\end{array}$ & 100 & 100 & AY364453 \\
\hline$T Y R$ & $\begin{array}{c}\text { 5'-CGATTCTTTATACATGAAATCTGTG -3' } \\
\text { 5'-AAACCGTTATAACAACGTGCTAA -3' }\end{array}$ & 113 & 111 & KV583276.1 \\
\hline 5- HTR & $\begin{array}{c}\text { 5'-CAGCTGCAAGATCGAGGATT -3' } \\
\text { 5'- TGAAGCCATCTTGACTGACG -3' }\end{array}$ & 144 & 117 & AB526218 \\
\hline
\end{tabular}

$\mathrm{EF} 1=M$. galloprovincialis elongation factor $-1 \alpha ; \mathrm{HEL}=M$. galloprovincialis helicase $; \mathrm{CS}=M$. galloprovincialis chitin synthase $; \mathrm{CA}=M$. edulis carbonic anhydrase; $\mathrm{EP}=M$. edulis extrapallial protein $; \mathrm{TYR}=M$. galloprovincialis tyrosinase; 5-HTR = M. edulis Serotonin receptor.

Effect of Thyroid receptor agonists/antagonists on early larval development

Fertilized eggs were exposed to thyroid hormones [3,3,5,5-triiodothyronine-T 4 (T2376, Sigma Aldrich) and 3,3,5-triiodothyronine- $\mathrm{T}_{3}$ (T6397, Sigma Aldrich)], the selective antagonist of human THR (1-850; 17248, Cayman Chemical Company) and Thiourea-TU (T8656, Sigma Aldrich). Stock 
solutions of $\mathrm{T}_{3}(0.3 \mathrm{M})$ and $\mathrm{T}_{4}(0.4 \mathrm{M})$ were prepared in $0.2 \mathrm{M}$ Sodium Hydroxide $(\mathrm{NaOH})$. For $\mathrm{TU}$ and 1-850, 6 and $0.2 \mathrm{M}$ stock solutions, respectively, were prepared in DMSO. Upon 10X serial dilution, fertilized eggs were exposed to final concentrations of $3,4,6$ and $2 \mu \mathrm{M}$ of $\mathrm{T}_{3}, \mathrm{~T}_{4}$, TU and 1-850, respectively. The effect on development was evaluated in 48 hpf larvae by phenotype scoring.

Effect of the dopamine antagonist SCH 23390 on early larval development

The role dopaminergic signalling in shell formation was first evaluated utilizing the selective antagonist of DR1, SCH 23390 (Liu et al., 2018). Fertilized eggs were exposed to R(+)-SCH-23390 hydrochloride (D054, Sigma Aldrich). A stock solution of SCH (0.5 M in DMSO) was diluted in MFSW at $500 \mu \mathrm{M}$ and tenfold diluted to obtain the final concentration $0.5 \mu \mathrm{M}$. Samples were analyzed by calcofulor/calcein staining at different times pf $(24,28,32,48 \mathrm{~h})$ and phenotypes evaluated at $48 \mathrm{hpf}$ as described above. 


\section{Results}

Figure S1 - Effect of THRs agonists and antagonists on larval development at 48 hpf.

Effects of $\mathrm{T}_{3}$ (3,3,5-triiodothyronine), $\mathrm{T}_{4}$ (3,3,5,5-triiodothyronine), 1-850 the selective antagonist of human THR, and Thiourea-TU on larval phenotypes: normally developed D-Veligers (white), with hinge malformations (light grey), pre-veligers (dark grey) and arrested trocophorae stage (black). Measurements were made on at least 50 larvae for each experimental condition obtained from 5 parental pairs $(\mathrm{N}=5)$.

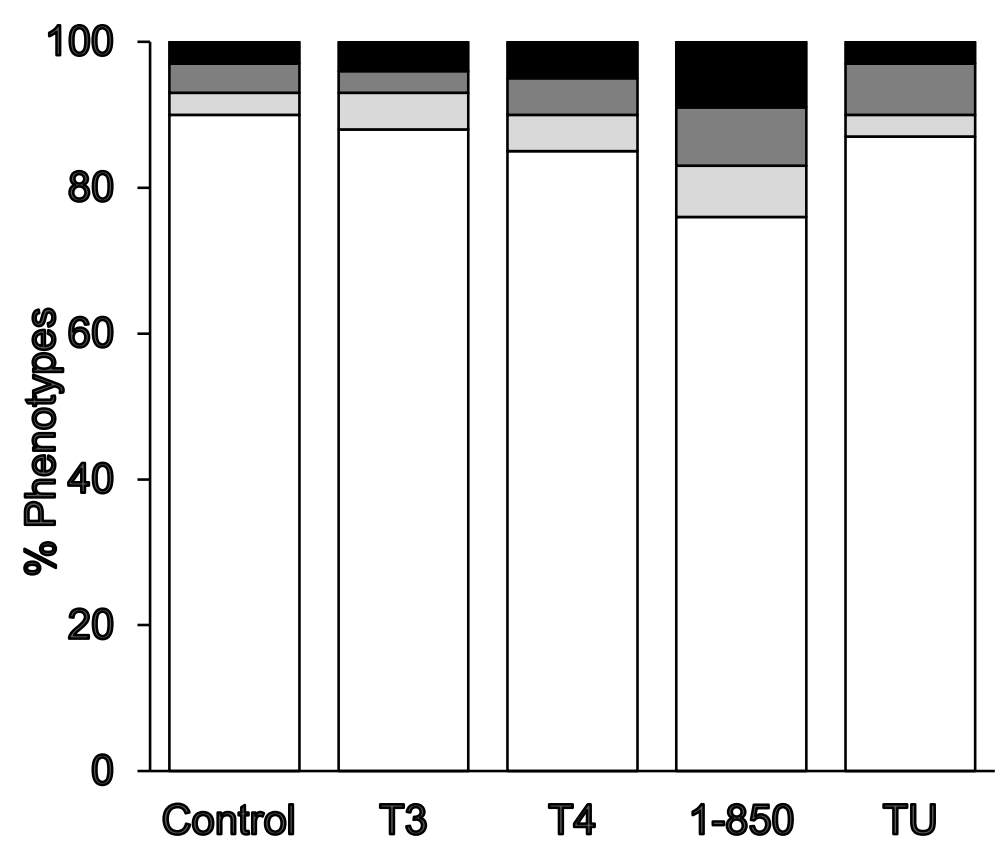


Figure S2 - Effects of the DOPA Receptor 1 (DR1) inhibitor SCH $23390(0.5 \mu M)$ on $M$. galloprovincialis larval development.

A) Calcofluor/calcein staining, showing organic matrix (blue) and calcified areas (green) in the growing shell at 24, 28, 32 and $48 \mathrm{hpf}$ as in Fig. 1B and Fig. 4. Due to the weakness of both signals, images of SCH samples were overexposed to show the shell field from 24 to $32 \mathrm{hpf}$ (arrowheads) and calcified areas at $48 \mathrm{hpf}$.

B) Areas of the organic matrix $\left(\mu \mathrm{m}^{2}\right)$ measured in a single valva of TBBPA-exposed larvae. Data are reported as \% values of control larvae at 24, 28 and 32 hpf. Details as in Fig. 5.

C) Percentage of larval phenotypes: normally developed D-Veligers (white), malformed larvae (light gray), immature larvae with protruding mantle (dark grey), arrested trochophorae (black). All details as in Fig. 1A.
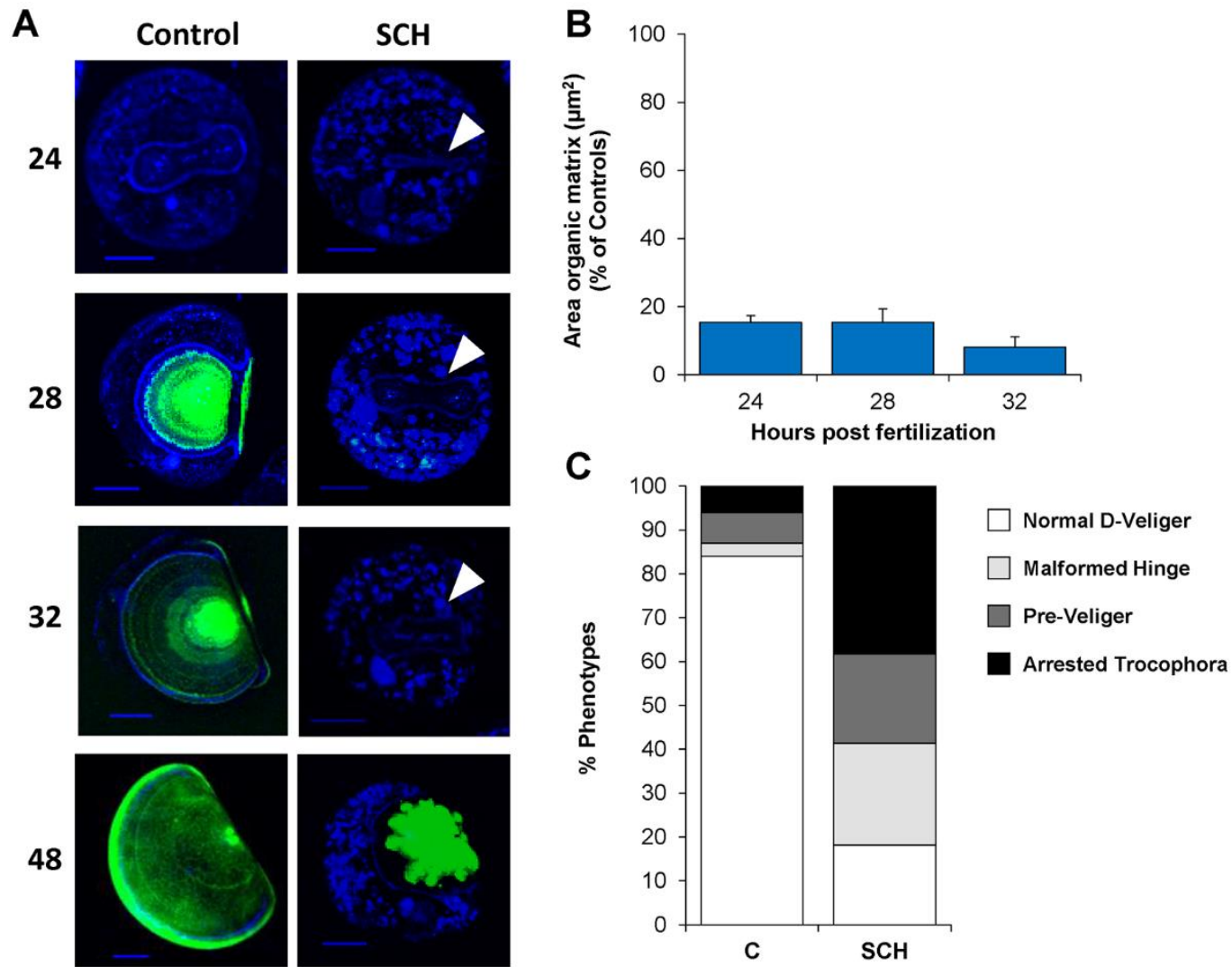
Figure S3 - GABA immunoreactivity and Hoechst staining in control (A) and TBBPA (10 $\mu \mathrm{g} / \mathrm{L})$ (B) exposed Mytilus larvae at 24, 28 and 32 hpf.

Larvae stained with GABA Ab were entirely imaged in 100 z-stacks, with Z-projections made every 10 sequential stacks (from z10 to z100). GABA-ir cells are shown in Red/Pink (Ex/Em: 590/617 nm), Hoechst stained nuclei are shown in blue (Ex/Em: 358/461 nm); the z-stack is indicated in white; the white dotted line indicates the perimeter of the larva. Scale bar: $20 \mu \mathrm{m}$.

A

24

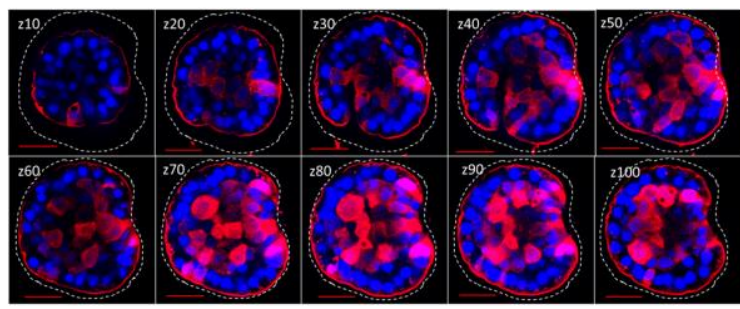

28

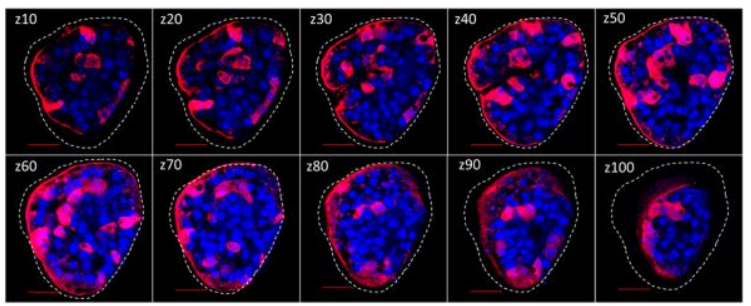

32

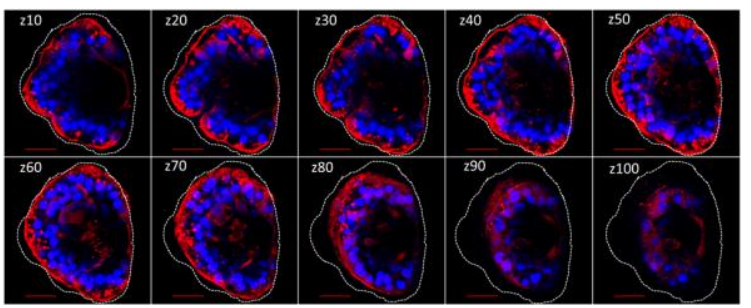

B

24

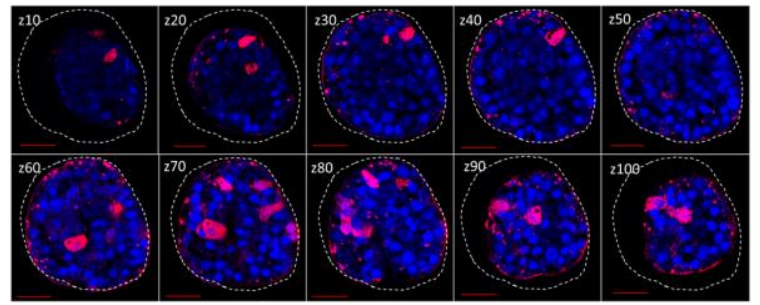

28

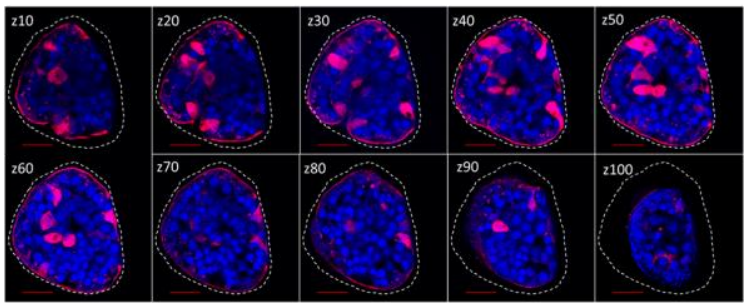

32

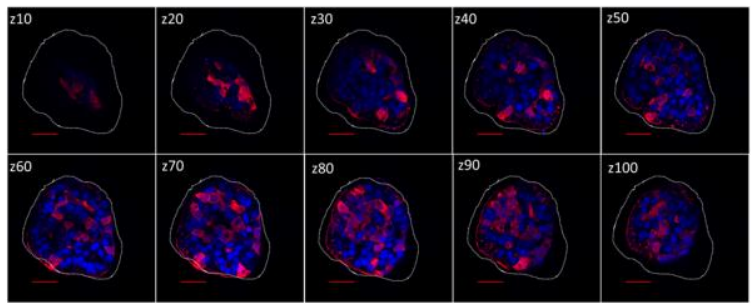


Figure S4 - GABA-ir and Hoechst staining at 48 hpf in control (A) and TBBPA-exposed larvae $(10 \mu \mathrm{g} / \mathrm{L})(\mathrm{B}-\mathrm{D})$.

Larvae stained with GABA Ab were entirely imaged in 100 z-stacks, with Z-projections made every 10 sequential stacks (from z10 to z100). GABA-ir cells are shown in Red/Pink (Ex/Em: 590/617 nm), Hoechst stained nuclei are shown in blue (Ex/Em: 358/461 nm); the z-stack is indicated in white; the white dotted line indicates the perimeter of the larva. Scale bar: $20 \mu \mathrm{m}$.

A) Normal D-veliger; B-D) altered phenotypes observed in TBBPA-exposed larvae; B) Indented hinge; C) Pre-veliger; D) Arrested trochophora.

A

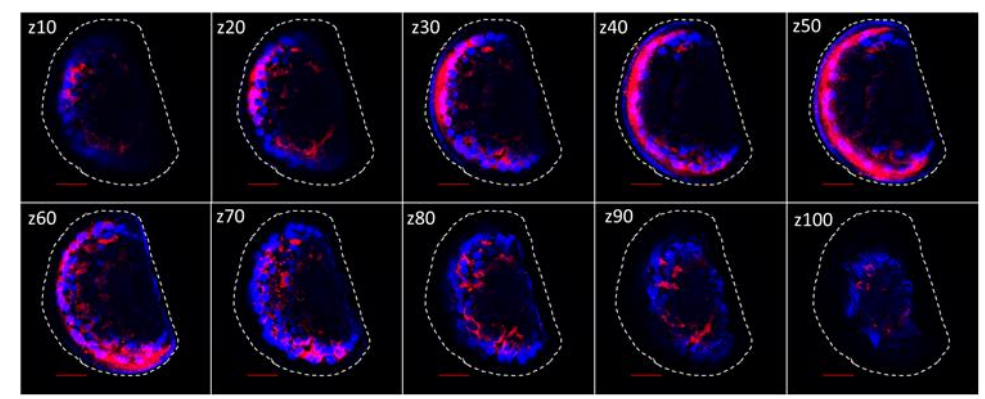

B

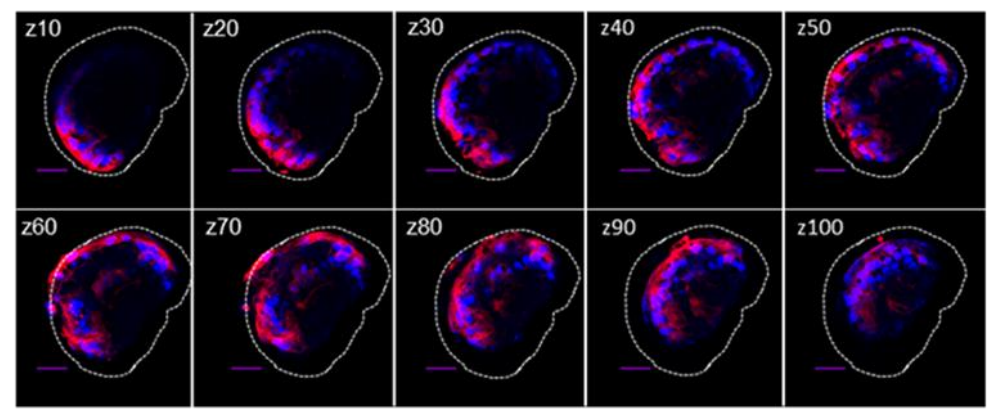

C

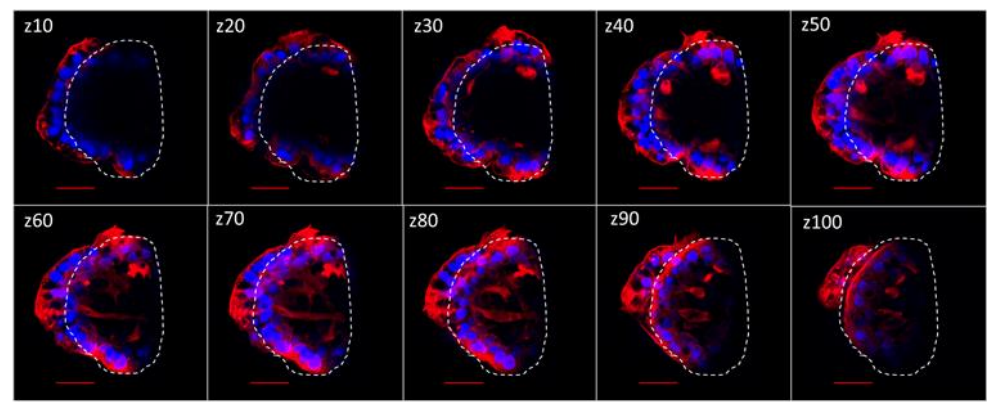

D

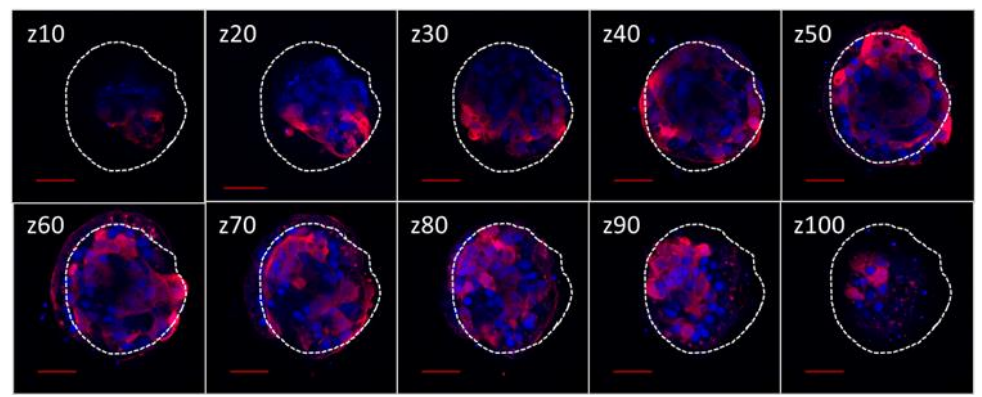

